\title{
Analytical and Experimental Studies With Idealized Gas Turbine Combustors
}

\author{
Fillmer W. Ruegg and Howard J. Klug
}

\begin{abstract}
Problems of flow, heat release, and mixing in gas turbine combustion chambers are discussed and analyzed. The analysis is based on an idealized or equivalent chamber in which the end result is the same as in the conventional chamber, but in which the functions are separate and distinct. A large primary zone is advantageous, but the combustion process still is burdened by an inverse relationship between primary air and fuel. Conditions favorable to combustion in the primary zone over the whole range of operation are realized by means of a mechanical control. Agreement between analysis and experiment was demonstrated by tests of a chamber with a mechanical control. Comparison of the field of mixing of primary flame gas and secondary air with other studies of mixing revealed a general similarity, but a slower rate of mixing that is ascribed to the effects of a large difference of temperature or density in these experiments.
\end{abstract}

\section{Introduction}

Although jet propulsion for aircraft has become a practical reality, many problems connected with it are still only partially solved. One of these problems is the development of combustion chambers for turbojet engines that will give satisfactory performance under all service conditions. Satisfactory performance implies that a continuous supply of exhaust gas at the desired temperature is furnished the turbine, and that response to demands for changes of conditions is positive and occurs in a minimum of time. Other desirable characteristics are high combustion efficiency, small loss of pressure, uniformity of temperature in the exhaust, minimum size and weight consistent with required performance and life, and ease of manufacture and maintenance. Some compromises have been necessary in designing combustion chambers, since some of these features have been found to be obtained only at the expense of others.

Problems of flow and combustion in conventional combustion chambers are so complicated and interrelated that development of chambers has progressed largely by empirical methods. Although development by these methods has produced immediate results, in the long run a fundamental understanding of the problem is advantageous and will promote design on a more rational basis. It is the purpose of this paper to separate and examine some of the functions of conventional gas turbine combustion chambers in an attempt to arrive at a better understanding of their influence on the performance of the chamber as a whole.

\section{Nomenclature}

$A=$ Area, $\mathrm{ft}^{2}$.

$c=$ Effectiveness of mixing.

$C=$ Coefficient in mixing length equation.

$c_{p}=$ Specific heat at constant pressure, $\mathrm{Btu} / \mathrm{lb}^{\circ} \mathrm{F}$.

$d, D=$ Diameter, ft.

$g=$ Standard acceleration of gravity, $\mathrm{ft} / \mathrm{sec}^{2}$.

$l=$ Mixing length, $\mathrm{ft}$.

1 The work deseribed in this report was sponsored by the Bureau of Aeronautics, Department of the Navy.
$L=$ Length of potential core, $\mathrm{ft}$.

$p=$ Absolute static pressure, $\mathrm{lb} / \mathrm{ft}^{2}$.

$p_{t}=$ Absolute total pressure, $\mathrm{lb} / \mathrm{ft}^{2}$.

$q=\frac{1}{2} \rho V^{2} ;$ dynamic pressure, $\mathrm{lb} / \mathrm{ft}^{2}$.

$r=$ Radius, $\mathrm{ft}$.

$r_{m}=$ Radius at which $T$ (or $V$ ) is halfway between $T$ (or $V$ ) at axis and that of secondary stream, $\mathrm{ft}$.

$R=$ Gas constant, $\mathrm{ft}-\mathrm{lb} / \mathrm{lb}{ }^{\circ} \mathrm{F}$.

$T=$ Absolute temperature, ${ }^{\circ} \mathrm{R}$.

$V=$ Velocity, $\mathrm{ft} / \mathrm{sec}$.

$W=$ Weight flow per unit time, $\mathrm{lb} / \mathrm{sec}$.

$x=$ Axial distance from station $3, \mathrm{ft}$.

$y=$ Lateral distance, $\mathrm{ft}$.

$z=$ Upper limit of probability integral.

$\epsilon=$ Emissivity.

$\eta_{b}=$ Combustion efficiency.

$\rho=$ Density, slugs $/ \mathrm{ft}^{3}$.

$\sigma=$ Scale factor.

T) $=$ Turbulent shear stress, $\mathrm{lb} / \mathrm{ft}^{2}$.

SUBSCRIPTS

1 to $4=$ Stations in the chamber.

$f=$ Fuel.

$i=$ Indicated.

$p=$ Primary.

$s=$ Secondary .

\section{Combustion Chamber}

Combustion chambers for gas turbines have been developed and modified according to the requirements of the system in which they are intended to be used. Although each chamber may be different from any other, it appears that most designs differ in detail only, and not in principle. An examination of the conventional combustion chamber reveals that there are four main functions that it must perform, (1) separation of the air into primary and secondary streams, (2) maintenance of a stable pilot zone, (3) combustion of fuel with the primary air, and (4) mixing of the burned gases with secondary air.

Design features may be illustrated by the schematic drawing in figure 1. A protected, turbulent zone of low velocity is established at $\mathrm{A}$ inside of the dome of the perforated liner, and when fuel is injected into this zone a mixture is formed which is capable of sustaining a stable flame. More air enters the liner between $\mathrm{A}$ and $\mathrm{B}$ and combustion proceeds as it 


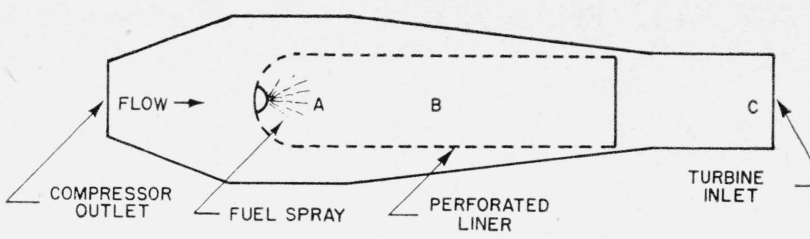

Figure 1. The conventional chamber.

$\mathrm{A}$, Turbulent zone of low velocity; A to B, primary zone; $\mathrm{B}$ to $\mathrm{C}$, mixing of secondary air with products of combustion from primary zone.

mixes with fuel. Velocity of the mixture in this zone is probably higher than the velocity of the flame in the mixture, but combustion is piloted by the flame from A. The air that takes part in the combustion in this zone is known as primary air. Secondary air enters and mixes with the products of combustion between $\mathrm{B}$ and $\mathrm{C}$, thereby reducing the gas temperature to a safe operating level. Completeness of combustion is promoted if the air is admitted gradually into the liner and in a manner so that it does not quench the flame and cause blowout.

There is no assurance that all of the air that enters the liner between A and B takes part in the combustion process, and therefore it may be said that the separation into primary and secondary air is not distinct.

Gas turbine combustors must be capable of operating over a wide range of exhaust to inlet temperature ratio, and generally this flexibility is attained by injecting atomized liquid fuel into the pilot zone at $A$. This method of fuel injection provides heterogeneous mixtures that are capable of supporting stable combustion, even though their quality may differ substantially from stoichiometric. It does not follow that combustion must always be efficient with this system. Actually, it may be good over only a narrow range of conditions, and may become poor when others are imposed.

Loss of pressure due to flow friction is high, and problems of flow and combustion are complicated and interrelated. Flow is turbulent, and in some regions within the primary zone, it may actually be in an upstream direction. Combustion and mixing within the liner nowhere occur as distinct, individual processes. Although these conditions appear to be beneficial from the standpoint of performance and flexibility, they make a detailed analysis of the conventional chamber almost an impossibility.

If a chamber is designed to carry out the functions enumerated above as separate and distinct operations, then an analysis of its performance becomes possible. A chamber designed for this purpose may be called an idealized or equivalent chamber, equivalent in the sense that the end result is the same as in the conventional chamber. The differences between this chamber, represented by figure 2, and one of conventional design are apparent. Stations A, B, and C in each figure represent locations where the same respective operations are performed. In this equivalent chamber the air is separated into two distinct streams, and the drop in pressure due to flow friction that each experiences is made to occur

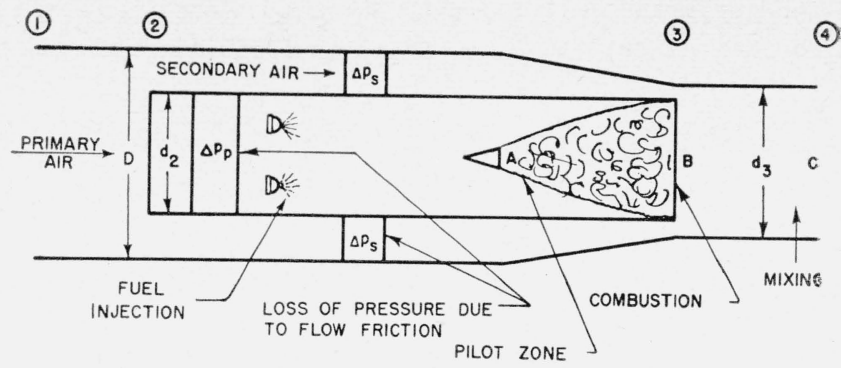

Figure 2. The equivalent chamber.

$\mathrm{A}$, Turbulent zone of low velocity; A to B, primary zone; B to C, mixing of secondary air with products of combustion from primary zone.

in a manner that is subject to analysis. A throttling process is assumed for the primary air, and the secondary air is assumed to go through a throttling process followed by a reversible expansion. Fuel is injected and combustion is stablized after the primary throttling process, and is assumed to be complete within the primary zone. The size of the pilot zone has been diminished to that which would exist at a flame holder, and combustion may be said to occur as in ramjet chambers. Since combustion is made to occur at a fixed temperature ratio in a stream that has a uniform, measureable velocity, the process is subject to treatment by both analytical and experimental methods. Mixing of the burned gas with secondary air occurs only after combustion is complete, and the changes resulting from this process also may be predicted and measured.

\section{Analysis of the Equivalent Combustion Chamber}

The method used in the analysis depends on the fact that each function of the combustion chamber is considered to be performed as a distinct, individual operation. Changes of temperature, pressure, etc. are calculated for each, and from these the performance of the chamber as a whole is derived.

Before these calculations may be made, it is necessary to specify some of the conditions at which the chamber is required to operate. Although any practical chamber must be able to operate over a wide range of conditions, there is usually some condition where it performs best, and it is desirable that this should coincide with the condition that is used most often in service. For the purpose of this analysis, an exhaust to inlet temperature ratio of 3.2 is a suitable specification, because it is close to that used in practice and is also a convenient working condition for experimental purposes.

As combustion is usually best when the mixture of air and fuel is at or near stoichiometric, this condition may be used as the basis of a second specification. A mixture of this quality would give an exhaust to inlet temperature ratio of about 7.25 across the primary zone.

Some loss of pressure in conventional chambers occurs when the air flows through the perforations of the liner. In order to approximate this condition in the chamber represented in figure 2 , it is necessary 
to introduce loss of pressure in the flow of air in a manner that its effects can be determined analytically and experimentally. Once the magnitude of the loss of pressure due to friction is specified, the configuration of the chamber may be calculated to satisfy all of the above specifications, provided the conditions of the flow in the chamber are also specified. However, the solution of the problem would apply only to the set of conditions of flow that were specified. Because an infinite number of conditions is possible and as all of them cannot possibly be handled, it is necessary to make a choice. The problem is simplified if it is considered that the velocity of flow in the chamber approaches zero, and this assumption is used throughout these analyses. Combustion chambers of gas turbines are operated at relatively low velocities; hence such an assumption would not cause serious errors.

Other simplifying assumptions may be made without serious error. These are: rise of temperature in the primary zone may be accomplished without adding fuel to the flowing stream; specific heat, $c_{p}$, of the gas is independent of temperature; loss of pressure due to friction does not occur except where stated; velocity of flow is uniform in each zone across planes in the duct normal to the flow; and secondary air receives no heat before it mixes with the gas at high temperature from the primary zone.

The problems of flow, heat release, and mixing may be handled by using Bernoulli's equation and the conservation of momentum equation. Since it is considered that the velocity of flow approaches zero, Bernoulli's equation for incompressible, frictionless flow may be written

$$
p+\frac{1}{2} \rho V^{2}=p_{t},
$$

where $p_{t}$ and $\rho$ are constant at all points in the flow. The conservation of momentum equation for heat release or mixing is

$$
p+\rho V^{2}=\text { constant },
$$

and when heat release occurs where $V$ approaches zero, eq 2 may be written

$$
V_{1 \rightarrow 0} \frac{p_{1}-p_{2}}{\frac{\rho_{1} V_{1}^{2}}{2}}=2\left(\frac{T_{2}}{T_{1}}-1\right) .
$$

The subscripts 1 and 2 in eq $2 \mathrm{a}$ indicate the state of the gas before and after heat release, respectively. When these equations are applied to cases where $V_{1}$ is appreciable, it is equivalent to considering that the fluid is incompressible, or that density is dependent only on temperature. The condition for continuity of flow may be written

$$
\rho A V=\text { constant. }
$$

Equations 1, 2, and 3 and the gas law, $p=g \rho R T$, are sufficient for the analysis of the problems of flow in the equivalent combustion chamber.

\subsection{Effect of Size of the Primary Zone}

Two design conditions of temperature rise in the chamber have been specified, but nothing has been said about the size of the primary zone. It would be possible to specify arbitrarily a size based on results of practical experience, but there is no assurance that the decision on this basis would be the most logical. A determination of the effect of size of the primary zone by analytical means probably would provide a sound basis on which to make a choice of size. This determination is attempted in the analysis that follows.

A list of the design conditions, in which the numerical subscripts refer to the stations in the chamber indicated in figure 2, is presented below. The subscripts $p$ and $s$ refer to primary and secondary air, respectively.

(1) $T_{4} / T_{1}=3.2 ;$ (2) $\quad T_{3, p} / T_{1}=7.25$; (3) $\Delta p_{s} / q_{2, s}=$ $2=$ loss of pressure due to flow friction ; (4) $\Delta p_{p} / q_{2, p}=$ $10=$ loss of pressure due to flow friction; (5) $p_{3, s}=p_{3, p}$.

At low velocity, loss of pressure due to friction may be expressed as a constant number of velocity heads, $q$, where $q=\frac{1}{2} \rho V^{2}$. The losses indicated in the third and fourth specifications were chosen in an attempt to approximate those in practical chambers. The fifth specification is that pressure is uniform across the plane of station 3 . Tollmien [1] ${ }^{2}$ calculated that the pressure at the plane of the discharge of a free, round jet differs from the ambient by an amount equal to about one-tenth percent of the dynamic pressure of the jet. A pressure difference of this small magnitude would have no significance in the present analysis. A variation of serious magnitude probably would not be encountered except where the velocity of flow in the primary stream at station 3 equaled the acoustic velocity in the stream. Conditions such as this are not encountered in present-day engines, and consequently are not considered here.

The above specifications provide sufficient information to permit a calculation of the effect of liner size, $d_{2}$, on the problems of flow, heat release, and mixing in the equivalent chamber.

If $W_{p}$ and $W_{s}$ are the rates of flow of the primary and secondary streams, respectively, then when mixing of these streams occurs between stations 3 and 4 , a heat balance may be written

$$
W_{p}\left(T_{3, p}-T_{4}\right) c_{p}=W_{s}\left(T_{4}-T_{1}\right) c_{p} .
$$

Noting that $c_{p}$ is assumed to be independent of temperature, eq 4 may be written

$$
\frac{W_{p}}{W_{p}+W_{s}}=\frac{\frac{T_{4}}{T_{1}}-1}{\frac{T_{3, p}}{T_{1}}-1},
$$

and when the first and second specifications are substituted, the right member of eq 5 is equal to

${ }^{2}$ Figures in brackets indicate the literature references at the of this paper. 

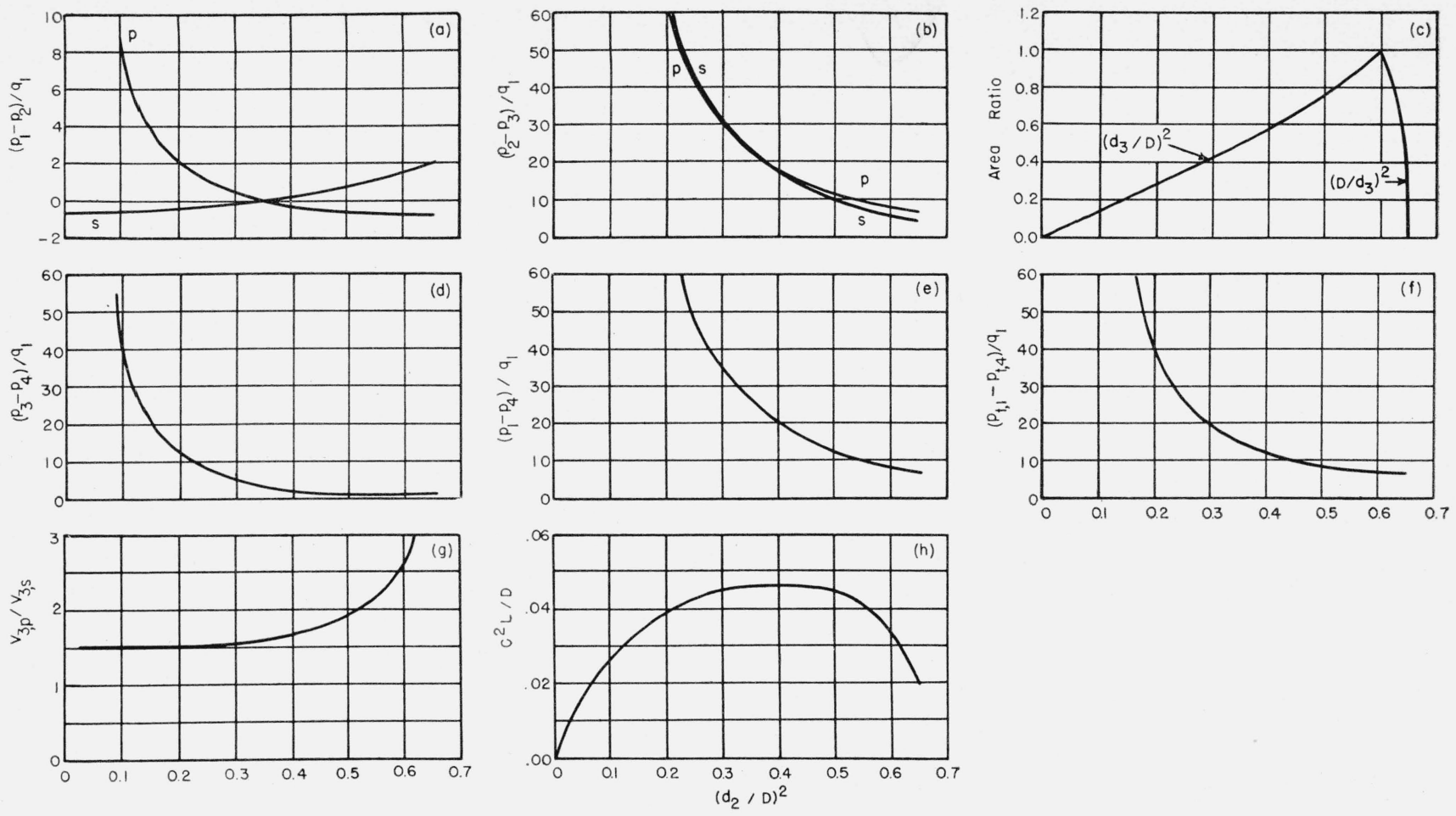

Figure 3. Effect of size of primary zone.

0.35. In other words, 35 percent of the air must enter the primary zone to fulfill the conditions of specifications (1) and (2). The air that enters the primary zone can be regarded as the central core of the stream at station 1 . Since it is considered that the properties of the flow are uniform at this station, the diameter of this central core of primary air can be expressed by the equation

$$
\left(d_{1} / D\right)^{2}=\frac{W_{p}}{W_{p}+W_{s}} .
$$

Bernoulli's equation, eq 1, may be used to determine the changes of pressure between stations 1 and 2 as $d_{2}$ is changed. Thus

$$
p_{1}-p_{2}=q_{2}-q_{1}=q_{1}\left(\frac{V_{2}^{2}}{V_{1}^{2}}-1\right),
$$

and the ratio of the velocities for both primary and secondary air may be determined by the continuity equation as follows:

$$
\begin{aligned}
& \left(\frac{V_{2, p}}{V_{1}}\right)^{2}=\frac{q_{2, p}}{q_{1}}=\left(\frac{d_{1} / D}{d_{2} / D}\right)^{4} \\
& \left(\frac{\boldsymbol{V}_{2, s}}{V_{1}}\right)^{2}=\frac{q_{2, s}}{q_{1}}=\left(\frac{1-d_{1}^{2} / D^{2}}{1-d_{2}^{2} / D^{2}}\right)^{2} .
\end{aligned}
$$

Since $\left(d_{1} / D\right)^{2}=W_{p} /\left(W_{p}+W_{s}\right)$, the pressure changes may be expressed by the equations

$$
\begin{aligned}
& p_{1}-p_{2, p}=q_{1}\left[\frac{\left(\frac{W_{p}}{W_{p}+W_{s}}\right)^{2}}{\left(\frac{d_{2}}{D}\right)^{4}}-1\right], \\
& p_{1}-p_{2, s}=q_{1}\left[\left(\frac{1-\frac{W_{p}}{W_{p}+W_{s}}}{1-\frac{d_{2}^{2}}{D^{2}}}\right)^{2}-1\right] .
\end{aligned}
$$

These were evaluated and plotted versus $\left(d_{2} / D\right)^{2}$ in figure 3 , a. When $\left(d_{2} / D\right)^{2}$ is greater than 0.35 , the primary air diffuses into the primary zone, its velocity decreases, and its pressure increases. When $\left(d_{2} / D\right)^{2}=0.6$, the velocity of the primary air as established by eq 8 is about 58 percent of $V_{1}$.

Loss of pressure in the primary zone is the sum of that due to friction and combustion. This may be written

$$
\left(p_{2}-p_{3}\right)_{p}=\Delta p_{p}+2 q_{2, p}\left(\frac{T_{3, p}}{T_{1}}-1\right),
$$

where the second term on the right side is determined by eq $2 a$, which is the loss due to combustion on the basis of the momentum equation. $q_{2, p} / q_{1}$ is given by eq 8 , and the pressure loss thus may be expressed in terms of $q_{1}$ by the following equation:

$$
\frac{\left(p_{2}-p_{3}\right)_{p}}{q_{1}}=\left[\frac{\Delta p_{p}}{q_{2, p}}+2\left(\frac{T_{3, p}}{T_{1}}-1\right)\right]\left(\frac{d_{1} / D}{d_{2} / D}\right)^{4}
$$


This was evaluated and the results are plotted in figure 3 , b.

Calculation of the change of pressure in the secondary air is based on the assumption that $p_{3, p}=p_{3, s}$. In order to fulfill this condition, it is necessary to change $d_{3}$ with $d_{2}$, and the required change may be evaluated by using eq 1 and 3 . Change of pressure in the secondary air may be written

$$
p_{2, s}-p_{3, s}=q_{3, s}-q_{2, s}+\Delta p_{s},
$$

and this may be solved for $p_{3, s} . \quad$ Eq 7 and 12 may be combined to yield

$$
p_{3, p}=p_{1}+q_{1}-q_{2, p}-\Delta p_{p}-2 q_{2, p}\left(\frac{T_{3, p}}{T_{1}}-1\right),
$$

and since it is considered that $p_{3, p}=p_{3, s}$, the right side of eq 15 may be substituted for $p_{3, s}$ in eq 14. By this method the following relation is derived,

$$
q_{3, s}=\left(p_{1}-p_{3}\right)+\left(q_{2, s}-\Delta p_{s}\right)-\left(p_{1}-p_{2}\right)_{s} .
$$

Now $q_{3, s}$ may be related to $q_{1}$ by the continuity equation, and this relation leads to

$$
\frac{q_{3, s}}{q_{1}}=\left(\frac{D^{2}-d_{1}^{2}}{d_{3}^{2}-d_{2}^{2}}\right)^{2}
$$

and when this is solved for $\left(d_{3} / D\right)^{2}$, the following is derived

$$
\left(\frac{d_{3}}{D}\right)^{2}=\frac{1-\frac{d_{1}^{2}}{D^{2}}}{\left(\frac{q_{3, s}}{q_{1}}\right)^{1 / 2}}+\frac{d_{2}^{2}}{D^{2}} .
$$

These equations furnish sufficient information to evaluate the change of pressure and of $d_{3}$ as $d_{2}$ is changed. Thus eq 14 and 16 evaluate $\left(p_{2, s}-p_{3, s}\right)$ and eq 16 and 18 evaluate $\left(d_{3} / D\right)^{2}$. Changes of pressure between stations 2 and 3 are plotted in figure $3, \mathrm{~b}$, and $\left(d_{3} / D\right)^{2}$ is plotted in figure 3, c. Both are plotted against $\left(d_{2} / D\right)^{2}$, which defines the size of the primary zone. Figure 3 , b, shows that the pressure loss decreases rapidly as the size of the primary zone is increased. However, the velocity in the secondary zone becomes high, and a point is reached (when $\left.\left(d_{2} / D\right)^{2}=0.6\right)$ where the loss in pressure across the throttle is so high that there is no need for more drop in pressure by expansion in the nozzle at station 3 . At this point $d_{3}=D$. If the primary zone were made still larger, the loss of pressure in the secondary air would be so high that an enlargement or diffuser would be necessary to recover and thus maintain the equality of pressure across station 3 . Thus $d_{3}$ would have to become larger than $D$, and this is shown in figure 3 , c, by the curve of $\left(D / d_{3}\right)^{2}$, where this ratio becomes zero when $\left(d_{2} / D\right)^{2}=0.65$. For all practical purposes, it may be said that the area of the primary zone in this chamber cannot exceed 60 percent of the total area. This area of the primary zone depends, of course, on the relative pressure losses in the primary and secondary zones. For example, if no friction loss were assumed, the maximum area would be 66 percent, whereas if both the assumed losses were doubled, the maximum area would decrease to 58 percent of the total.

At station 3 the primary air at high temperature and the secondary air begin to mix, and the resulting changes of pressure may be calculated by the equation for the conservation of momentum. For this case it may be written

$$
\left(p_{3}+2 q_{3, s}\right)\left(1-\frac{d_{2}^{2}}{d_{3}^{2}}\right)+\left(p_{3}+2 q_{3, p}\right) \frac{d_{2}^{2}}{d_{3}^{2}}=p_{4}+2 q_{4} .
$$

This equation may be arranged to the more convenient form

$$
\frac{p_{3}-p_{4}}{q_{1}}=2 \frac{q_{4}}{q_{1}}-2 \frac{q_{3, s}}{q_{1}}\left(1-\frac{d_{2}^{2}}{d_{3}^{2}}\right)-2 \frac{q_{3, p}}{q_{1}}\left(\frac{d_{2}}{d_{3}}\right)^{2},
$$

and the change of pressure is determined by evaluating each of the separate terms and taking the sum. These terms may be evaluated by using the continuity equation and the gas law, and always considering that $\rho$ is dependent only on temperature. Thus

$$
\begin{gathered}
2 \frac{q_{4}}{q_{1}}=2 \frac{T_{1}}{T_{4}}\left(\frac{T_{4}}{T_{1}} \frac{D^{2}}{d_{3}^{2}}\right)^{2}=2 \frac{T_{4}}{T_{1}}\left(\frac{D}{d_{3}}\right)^{4}, \\
2 \frac{q_{3, s}}{q_{1}}\left(1-\frac{d_{2}^{2}}{d_{3}^{2}}\right)=2\left(\frac{D^{2}-d_{1}^{2}}{d_{3}^{2}-d_{2}^{2}}\right)^{2}\left(1-\frac{d_{2}^{2}}{d_{3}^{2}}\right), \\
2 \frac{q_{3, p}}{q_{1}}\left(\frac{d_{2}}{d_{3}}\right)^{2}=2 \frac{T_{1}}{T_{3, p}}\left(\frac{d_{1}^{2}}{d_{2}^{2}} \frac{T_{3, p}}{T_{1}}\right)^{2}\left(\frac{d_{2}}{d_{3}}\right)^{2}=2 \frac{T_{3, p}}{T_{1}} \frac{d_{1}^{4}}{d_{2}^{2} d_{3}^{2}} .
\end{gathered}
$$

The values of these terms were determined from the previous relations, and the sum expressed as $\left(p_{3}-p_{4}\right) /$ $q_{1}$ is plotted versus $\left(d_{2} / D\right)^{2}$ in figure 3 , d. The overall change of pressure from station 1 to 4 , which was evaluated by a summation of the successive changes, is plotted versus $\left(d_{2} / D\right)^{2}$ in figure 3 , e.

Although the over-all change of pressure is informative, it does not allow ready comparison with the change of pressure of other combustion chambers. In order to make a comparison on this basis, it would be necessary for each chamber to have inlet and exhaust ducts of the same relative size. However, if the loss of pressure is expressed in the fundamentally more useful form of total pressure, a comparison is possible without this information about size. Loss of total pressure may be written

$$
\frac{p_{t, 1}-p_{t, 4}}{q_{1}}=\frac{p_{1}-p_{4}}{q_{1}}-\frac{q_{4}}{q_{1}}+1
$$

The first two terms on the right side were evaluated previously (see fig. 3, e, and eq 20), and the loss of total pressure was determined and is plotted versus $\left(d_{2} / D\right)^{2}$ in figure 3, f. Inspection of this curve reveals the advantage of a liner of large size. When the liner of this chamber occupies 60 percent of the total area, the loss of pressure is about half that when the liner occupies 35 percent of the area. 
Little is known about the factors that control the rate of mixing of gas streams under conditions that exist in combustion chambers. In practical chambers the rate is accelerated by the turbulent flow of the air through the perforations of the liner. Although this is accomplished at the expense of loss of pressure, it is compensated for by the consequent reduction in length of the chamber. One of the factors that may influence the rate of mixing is the ratio of the velocity of the gas streams at station 3 . The ratio of $q_{3, p} / q_{3,8}$ may be determined from eq 21 and 22 , and noting that $T_{3, p} / T_{1}=7.25$, the velocity ratio may be derived, and equals

$$
\frac{V_{3, p}}{V_{3, s}}=\frac{T_{3, p}}{T_{1}}\left(\frac{d_{1}}{d_{2}}\right)^{2} \frac{\left(\frac{d_{3}}{D}\right)^{2}-\left(\frac{d_{2}}{D}\right)^{2}}{1-\left(\frac{d_{1}}{D}\right)^{2}} .
$$

This was evaluated and the ratio is plotted versus $\left(d_{2} / D\right)^{2}$ in figure $3, \mathrm{~g}$. It increases with an increase of the size of the liner, notwithstanding the fact that $V_{2, p}$, and therefore $V_{3, p}$, decreases. The degree of expansion required in the secondary stream also decreases, and $V_{3, s}$ decreases at a greater rate than $V_{3, p}$.

Squire and Trouncer [2] analyzed the problem of incompressible mixing of a round jet in a general stream, and the results were used here in an attempt to determine the effect of liner size on the mixing of the primary and secondary streams. Although the conditions existing in a combustion chamber differ in many respects from those assumed in the analysis, it is possible that the two cases would exhibit similar behavior.

In the analysis [2] the momentum transfer theory was used to determine the way in which velocity is transferred between two round streams. Turbulent shear stress, $\tau$, defined by the equation

$$
\tau=\rho l^{2}\left(\frac{d V}{d r}\right)^{2}
$$

was equated to the change of momentum flux of the mixing region with axial distance. Mixing length, $l$, was assumed equal to the width of the mixing region multiplied by a constant of proportionality, $C$. The constant $C$ was considered a characteristic of the turbulent motion, and appeared in the end result as a constant to be evaluated experimentally. It was also assumed that the variation of velocity across the mixing region was similar to that determined by the cosine equation

$$
\frac{V-V_{s}}{V_{r=0}-V_{s}}=\frac{1}{2}\left(1+\cos \frac{\pi r}{2 r_{m}}\right)
$$

where $r_{m}$ is the radius at which velocity is half way between axial and secondary stream velocity. Regions in the flow and significance of terms in eq 26 are illustrated in figure 4.

Extent of the potential core of undisturbed primary stream, $L / d_{2}$, was found to increase as the ratio

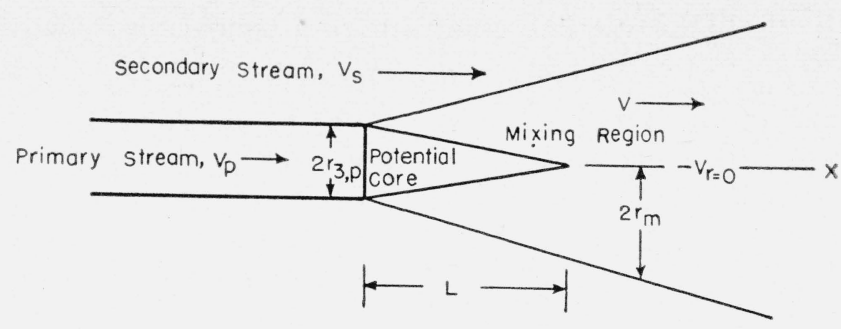

Figure 4. Diagram of mixing field.

of primary to secondary stream velocity, $V_{3, p} / V_{3, s}$ decreased and approached unity. Beyond $L$, the rate of decay of velocity along the axis was not influenced greatly by $V_{3, p} / V_{3, s}$, and therefore for the present present purposes $L$ may be regarded as an inverse measure of the effectiveness of the mixing process in bringing the two streams to a uniform state. In other words, at a given value of axial distance $x$, $(x>L)$, decay along the axis would be less complete when $L$ is large.

Squire and Trouncer present values of $L / d_{2}$ and $V_{3, p} / V_{3, s}$, and in this analysis the variation of $V_{3, p} / V_{3, s}$ with $d_{2} / D$ has been determined. A combination of the two sets of information will allow determination of $L$ as a function of $d_{2}$, and this is presented in figure $3, \mathrm{~h}$. In their analysis the constant $C$ was regarded as independent of $V_{3, p} / V_{3, s}$, and this same assumption is made here. At small values of $d_{2}, L$ is also small, and mixing would probably be good. As $d_{2}$ is increased, $V_{3, p} / V_{3, s}$ increases slowly, but not sufficiently to counterbalance increase of $d_{2}$, and $L$ increases. However, a point is reached where $V_{3, p} / V_{3, s}$ increases at a rate sufficient to counterbalance increase of $d_{2}$, and $L$ begins to decrease. When $\left(d_{2} / D\right)^{2}=0.6, L$ is well below the maximum, and it may be said that mixing probably would be relatively effective at this condition. In connection with these conclusions, it must be remembered that there are differences between the conditions assumed in the theory and those existing in a chamber. A large difference of temperature, confinement of the mixing region by the walls of the chamber, and a relatively large primary stream would probably influence the mixing in a manner that would require experimental determination.

This analysis has indicated the effect of the size of the primary zone on the problems of flow, heat release, and mixing in the equivalent chamber. A primary zone of large size appears to offer the advantages of low velocity in the primary zone, and reduced loss of pressure across the chamber. Low velocity probably would simplify the problem of maintenance of a stable flame, and a reduction in the loss of pressure would increase the "mechanical efficiency" of the chamber and thereby increase the over-all efficiency of the engine in which it would be used. With regard to the problem of mixing, the analysis indicates no serious disadvantage attached to a large primary zone. Maximum area of the primary zone in the equivalent chamber is found to be 60 percent of the total chamber area. Measurements of practical chambers indicate that the area 
of the primary zone is generally about 60 percent of the total, and this point of similarity between analysis and practice is gratifying. For these reasons the size of the primary zone is fixed at the maximum value in the analysis that follows.

\subsection{Analysis of Operation of the Equivalent Combustion Chamber}

The only means of control over the over-all temperature ratio in conventional chambers is by the variation of the rate of fuel injection into the primary zone. This may be approximated for purposes of analysis by assuming that the temperature ratio, $T_{3, p} / T_{1}$, in the primary zone is allowed to change, while holding the configuration of the chamber constant, as determined above. Before proceeding to the calculations, it is advantageous to list the following complete specifications for this combustion chamber:

(1) $d_{2}^{2}=0.6 D^{2} ;$ (2) $d_{3}=D$; (3) $\Delta p_{s} / q_{2, s}=2=$ loss of pressure due to flow friction; (4) $\Delta p_{p} / q_{2, p}=10=$ loss of pressure due to flow friction; (5) $p_{3, s}=p_{3, p}$; (6) $T_{4} / T_{1}$ varies with $T_{3, p} / T_{1}$.

The problem is to evaluate the distribution of air between the primary and secondary zones on the basis that $p_{3, p}$ will always equal $p_{3, s}$. Exhaust to inlet temperature ratio, $T_{4} / T_{1}$, can be determined once the distribution is known. Loss of pressure in the primary zone is given by eq 12 , and by using eq $1, p_{2, p}$ may be written in terms of $p_{1}$, as follows:

$$
p_{2, p}=p_{1}+q_{1}-q_{2, p}
$$

Combining these two equations gives

$$
\left(p_{1}-p_{3}\right)_{p}=q_{2, p}\left(\frac{\Delta p_{p}}{q_{2, p}}+2 \frac{T_{3, p}}{T_{1}}-1\right)-q_{1} .
$$

Loss of pressure in the secondary air is given by eq 14 , and by evaluating $p_{2, s}$ in terms of $p_{1}$ and combining, there results

$$
p_{1}-p_{3, s}=2 q_{2, s}+q_{3, s}-q_{1} .
$$

Equating 28 and 29 on the assumption that $p_{3, p}=p_{3, s}$ yields

$$
q_{2, p}\left(\frac{\Delta p_{p}}{q_{2, p}}+2 \frac{T_{3, p}}{T_{1}}-1\right)=2 q_{2, s}+q_{3, s} .
$$

Since $d_{3}$ is specified equal to $D, q_{2, s}=q_{3, s}$, and eq 30 will yield a relation between $q_{2, p}, q_{2, s}$ and $T_{3, p} / T_{1}$, as follows:

$$
\frac{q_{2, s}}{q_{2, p}}=\frac{\Delta p_{p} / q_{2, p}+2\left(T_{3, p} / T_{1}\right)-1}{\left(\Delta p_{s} / q_{2, s}\right)+1} .
$$

This equation, when combined with the equation of continuity of flow,

$$
(\rho V A)_{\mathrm{i}}=\frac{W_{p}}{g}+\frac{W_{s}}{g}=(\rho V A)_{2, p}+(\rho V A)_{2, s}
$$

will yield a relation that will predict how the air divides between the primary and secondary zones as $T_{3, p} / T_{1}$ is changed. Thus the continuity equation may be written in the form

$$
\frac{W_{p}}{W_{p}+W_{s}}=\frac{1}{1+\frac{V_{2, s}}{V_{2, p}} \frac{D^{2}-d_{2}^{2}}{d_{2}^{2}}},
$$

and since $V_{2, s} / V_{2, p}=\left(q_{2, s} / q_{2, p}\right)^{1 / 2}$, the fraction of air going into the primary zone is

$$
\frac{W_{p}}{W_{p}+W_{s}}=\frac{1}{1+\left[\frac{\Delta p_{p} / q_{2, p}+2\left(T_{3, p} / T_{1}\right)-1}{\Delta p_{s} / q_{2, s}+1}\right]^{1 / 2}\left(\frac{D^{2}}{d_{2}^{2}}-1\right)} .
$$

Equation 5 expresses the relation between $T_{4} / T_{1}$ and $W_{p}\left(W_{p}+W_{s}\right)$, and this may be combined with eq 34 to yield

$$
\frac{T_{4}}{T_{1}}=1+\frac{\frac{T_{3, p}}{T_{1}}-1}{1+\left[\frac{\Delta p_{p} / q_{2, p}+2\left(T_{3, p} / T_{1}\right)-1}{\Delta p_{s} / q_{2, s}+1}\right]^{1 / 2}\left(\frac{D^{2}}{d_{2}^{2}}-1\right)} .
$$

This expresses the relation between the overall temperature ratio and the temperature ratio in the primary zone, and is plotted in figure 5, a. The relation between $T_{4} / T_{1}$ and $W_{p} /\left(W_{p}+W_{s}\right)$ is plotted in figure $5, \mathrm{~b}$.

Inspection of these curves reveals some interesting information concerning the operation of the chamber. Although $T_{3, p} / T_{1}$ increases with $T_{4} / T_{1}$, the fraction of air going into the primary zone decreases. This may be interpreted to mean that as more fuel is injected into the primary zone, the flow of air into it will decrease. Thus the length of the flame will increase with $T_{4} / T_{1}$, and at values higher than the design condition it may extend downstream beyond the primary zone. Mixing with secondary air may not be complete by the time the gas enters the turbine, and the turbine may be exposed to gas at excessively high temperatures. A further possibility is that the conditions may not be favorable for combustion beyond the primary zone. The flame may be quenched by the large quantity of excess air, and combustion efficiency will then be low. In addition, the pilot zone may become so rich in fuel that it will not support combustion, and rich blowout will occur.

Conversely, at low values of $T_{4} / T_{1}$, the mixture in the primary zone will be lean in fuel, and combustion may be poor. As $T_{4} / T_{1}$ is decreased, a point will be reached where the mixture in the primary zone will be too lean to support combustion, and lean blowout will occur. Moreover, the velocity in the primary zone increases and adds to the difficulty. These effects are observed in testing of practical chambers, although not exclusively because of the reasons enumerated. 

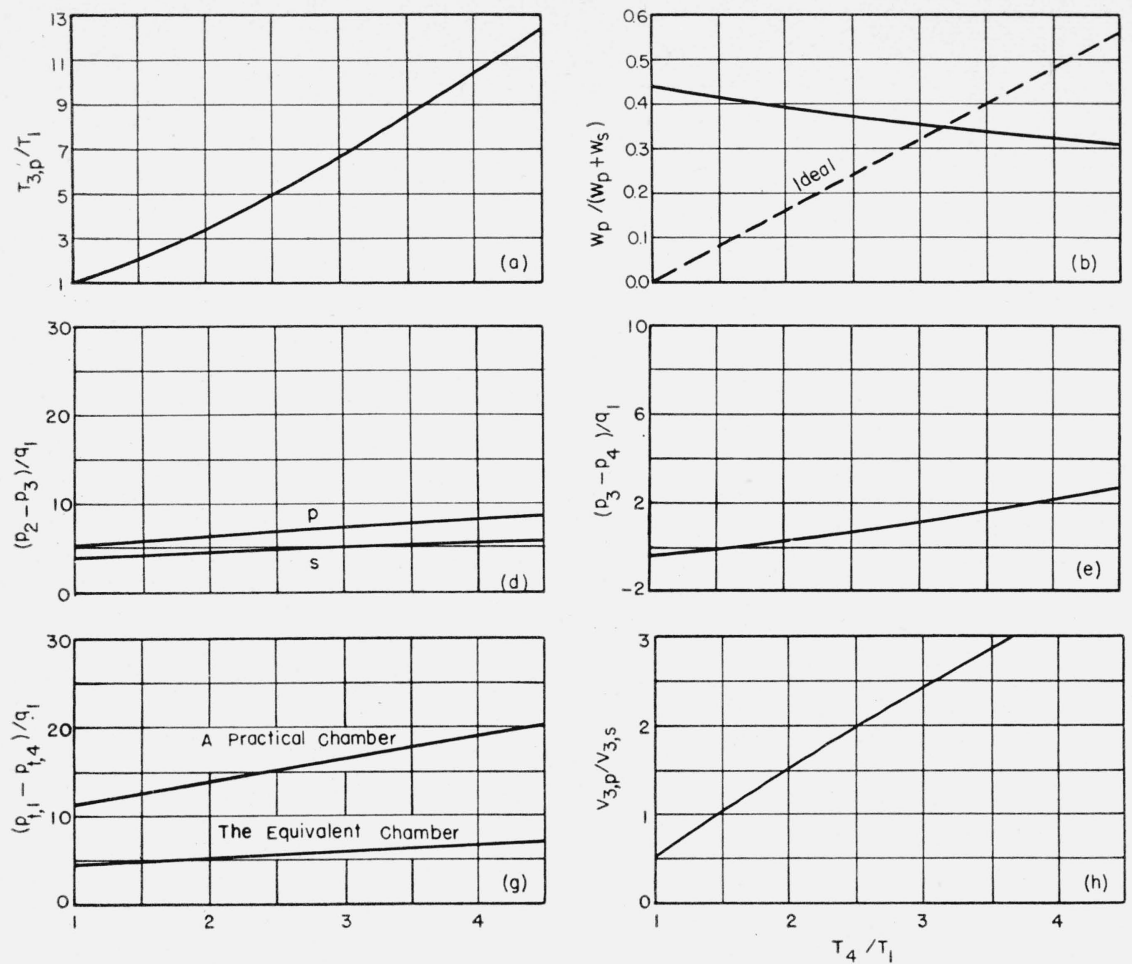
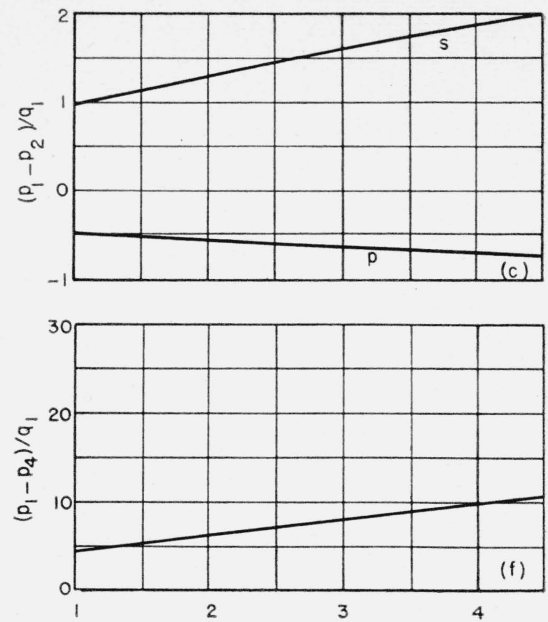

Figure 5. Effects in the chamber with a large primary zone.

In contrast to the air distribution determined above, a distribution is shown based on maintenance of near stoichiometric conditions in the primary zone. Equation 5 was used with a constant value of $T_{3, p} / T_{1}$ equal to 7.25 , and the dotted curve labeled "ideal" in figure 5, b, i s the result. This ideal distribution is radically different and points out the fact that the conventional chamber has proper distribution only at the design condition, that is, at the value of $T_{4} / T_{1}$ where the two curves cross.

Both the type of mixture of air and fuel and the velocity of the air in the combustion chamber influence the lean and rich limits of combustion. Heterogeneous mixtures are used exclusively because the range of combustible limits is relatively wide compared to that of homogeneous mixtures. It is probably true that low velocity tends to widen the limits in all chambers of this type.

When the distribution of the air is known, the changes of pressure and velocity in the chamber may be determined. Because the fraction of air going into the primary zone changes with $T_{4} / T_{1}$, it is evident that the streamlines of this air will diverge or converge on going from station 1 to 2 , depending on the quantity that is flowing. If this fraction is smaller than that of the fraction of the area included by the primary zone, the streamlines will diverge, and the air will diffuse into the primary zone. Change of pressure between stations 1 and 2 may be determined as before by eq 5 to 11 , remembering in this case that the fraction of primary air is the variable. A plot of these is presented in figure 5 , c, for both primary and secondary air streams. At all values of $T_{4} / T_{1}$ the primary air in this chamber diffuses into the primary zone, whereas the secondary air expands.
The changes of pressure between stations 2 and 3 are evaluated by combining eq 28 and 10 for the primary zone, and 28 and 11 for the secondary zone. 'Thus by this method

and

$$
p_{2, p}-p_{3}=\left(p_{1}-p_{3}\right)-\left(p_{1}-p_{2, p}\right),
$$

$$
p_{2, s}-p_{3}=\left(p_{1}-p_{3}\right)-\left(p_{1}-p_{2, s}\right) .
$$

These changes were evaluated, and the results are plotted in figure $5, \mathrm{~d}$. For this chamber the loss in static pressure from station 2 to 3 does not change greatly with $T_{4} / T_{1}$.

Mixing of the primary and secondary streams begins at station 3 , and the change of pressure that results may be calculated as before by eq 19 through 22. This is plotted in figure 5, e, and the over-all change of pressure from station 1 to 4 is plotted in figure 5, f. Loss of total pressure may also be evaluated as before (see eq 23), and is plotted in figure $5, \mathrm{~g}$. In this equivalent chamber the total loss is about $6 q_{1}$.

Observed loss of total pressure in a practical combustion chamber is also shown for comparison. These data were observed when $V_{1}$ was equal to 70 $\mathrm{ft} / \mathrm{sec}$, and displacement of the curves from each other is an indication of the relative magnitude of the loss of pressure due to friction. Loss of pressure in a combustion chamber is undesirable, because it lowers the over-all efficiency of the engine in which it is used, and from this standpoint it appears that this equivalent chamber would be superior. However, size and performance of the chambers in other respects must also be considered before an effective 
comparison can be made. Combustion efficiency, stability, etc. are very important, but all the factors that influence these are not thoroughly understood. Such factors as pressure, temperature, character of the mixture of air and fuel, etc. may not have the same effects in all combustion chambers, and these are not considered in this analysis. Their influence in any one chamber is determined almost exclusively by experiment.

The ratio of the velocities of the primary to secondary air at station $3, V_{3, p} / V_{3, s}$ was evaluated as before (see eq 24) and is plotted versus $T_{4} / T_{1}$ in figure $5, \mathrm{~h}$. It increases with $T_{4} / T_{1}$, and probably the mixing process will be most effective in bringing the gas to a uniform state when outlet temperature is high. Effective mixing is needed most at this condition of high temperature.

The combustion chamber described and analyzed is similar to practical chambers in which over-all ratio of temperature $T_{4} / T_{1}$ is controlled by rate of fuel injection into the primary zone. In the analysis this method of control is simulated by variation of temperature ratio, $T_{3, p} / T_{1}$, in the primary zone. It has been pointed out that this system of control has certain undesirable effects in the combustion chamber. When the conditions of operation deviate from the design point, the quality of the mixture of air and fuel in the primary zone also deviates from the quality that is most favorable for combustion. Hence the efficiency of combustion probably would decrease, and at extreme conditions the mixture would become either too rich or lean to support combustion. It is recognized that this system has certain advantages, such as simplicity of control, because all that is required is a control of the rate of fuel injection into the primary zone. However, the advantages of maintaining conditions for good combustion are also apparent, and some effort may well be made to investigate the requirements for this objective.

\subsection{Analysis of Operation of a Chamber with a Controlled Primary Zone}

As stated before, combustion is usually best when the mixture of air and fuel is near stoichiometric, and hence $T_{3, p} / T_{1}$ may be selected to be equal to 7.25 as before. The problem then is to select a method and determine the conditions that are necessary to hold $T_{3, p} / T_{1}$ constant while $T_{4} / T_{1}$ is varied. Probably the first method that comes to mind is the variation of the size of the mixing section, since this method was used in the first analysis. In that analysis $d_{2}$ was varied, and $d_{3}$ was changed simultaneously to hold $T_{3, p} / T_{1}$ constant. This method would require an adjustable nozzle at station 3 , and in service it probably would be impractical. However, an adjustable throttle, or valve, also may be inserted in the secondary zone for this purpose. Although this method of control introduces loss of pressure due to friction, it has certain advantages from the standpoint of mechanical simplicity. A combustion chamber with such a device is represented by figure 6 , where the throttle takes the form of two perforated, thin annuli. The pressure drop in the secondary

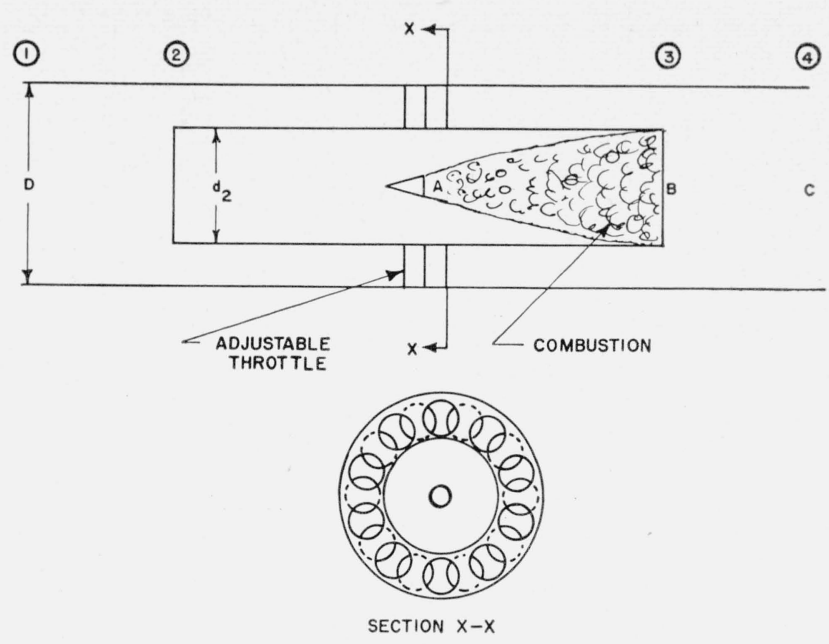

FIGURE 6. Diagram of the chamber with the controlled primary zone.

stream is adjusted by rotating one annulus relative to the other, thus providing larger or smaller openings as desired. This is only one of many possible schemes that might accomplish the same object. It will, however, serve for the purposes of this analysis.

The specifications for this case are (1) $T_{3, p} / T_{1}=$ $7.25 ; \quad(2) \quad d_{2}^{2}=0.35 D^{2}$; (3) $d_{3}=D$; (4) $\Delta p_{p}=0$; (5) $p_{3, s}=p_{3, p} ;(6) T_{4} / T_{1}$ varies with $\Delta p_{s} / q_{2, s}$.

Stations in the chamber are shown in figure 6 . It will be noted that $d_{2}$ was specified small $\left(0.35^{1 / 2} D\right)$, and this was done for several reasons. Experimental work was planned on this chamber, and it appeared that conditions in a small primary zone would be more favorable in the proposed experiments to a well-regulated combustion process. In a large zone the velocity of the primary stream would be low, and probably the flame would seat at the fuel injector under some conditions, and under others would require a flame holder for stabilization. In a small zone, velocity would be relatively high, and combustion could be well regulated and performed in a homogeneous mixture of air and fuel with the seat of the flame at any desired position. A large primary zone would require a throttle in the primary stream, with attendant increase of mechanical problems and unknown effects on the flow conditions and combustion process. Another reason for a small zone was that a study of the mixing process of flame gas and secondary air could be made under conditions more nearly comparable with those assumed in theoretical studies of spread of free jets and of mixing of coaxial streams. The particular size chosen for the primary zone is that for which the flow of air will be undisturbed when operating at the design condition of $T_{4} / T_{1}=3.2$. At this design condition primary air is 35 percent of the total (see eq 5). With regard to the specification of no pressure loss due to friction in the primary zone, this is not a serious departure from reality because the loss can be made small when combustion is performed under the conditions mentioned. These specifications of the method of combustion and of 

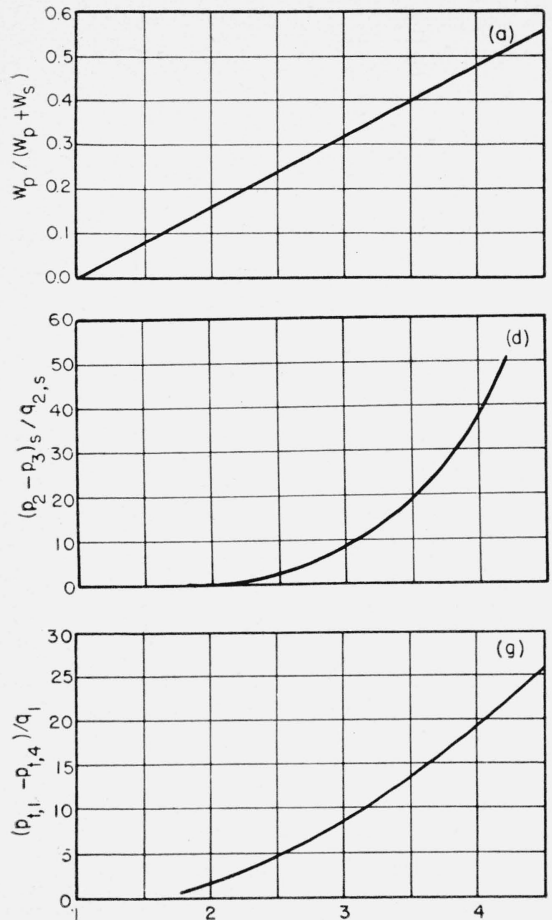
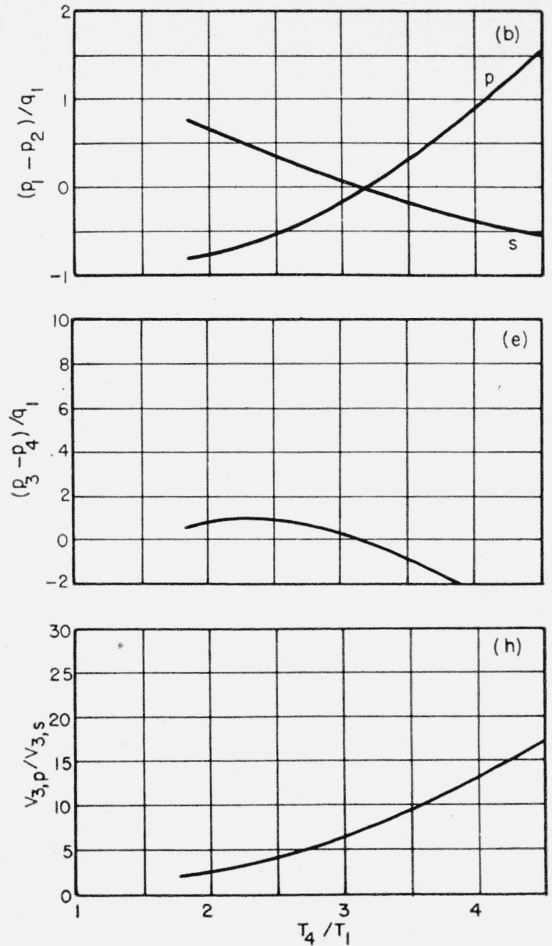
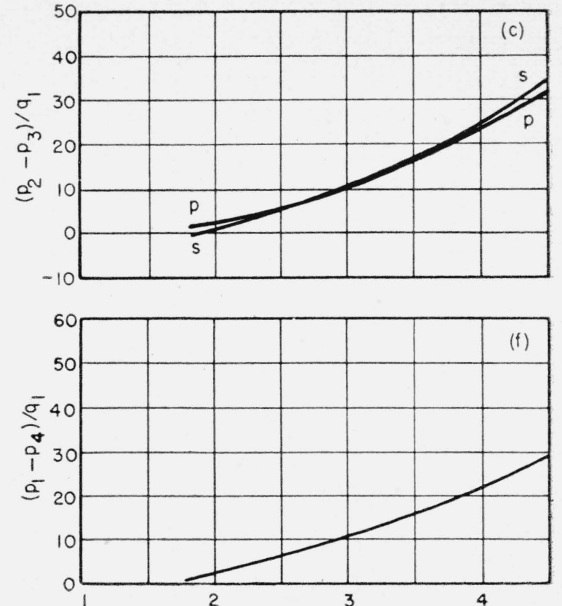

FIGURE 7. Effects in the chamber with the controlled primary zone.

pressure loss in the primary zone, although practical in the laboratory, probably would not be practical in actual engines where flexibility of operation is important.

The fraction of air going into the primary zone under the conditions specified may be calculated again by eq 5 , using $T_{3, p} / T_{1}$ constant at 7.25. Results of these calculations are shown in figure 7, a. Change of pressure in the primary and secondary air between stations 1 and 2 may be calculated by using eq 10 and 11 , and these changes are shown in figure $7, \mathrm{~b}$.

Loss of pressure in the primary zone is

$$
\left(p_{2}-p_{3}\right)_{p}=2\left(\frac{T_{3, p}}{T_{1}}-1\right) q_{2, p},
$$

and in order to evaluate 38 it is necessary to express $q_{2, p}$ in terms of $q_{1}$. By Bernoulli's equation, eq 1, $q_{2, p}$ may be written

$$
q_{2, p}=\left(p_{1}-p_{2}\right)_{p}+q_{1},
$$

and since $\left(p_{1}-p_{2}\right)_{p}$ is determined by eq 10 , eq 38 and 39 may be combined to yield:

$$
\left(p_{2}-p_{3}\right)_{p}=2 q_{1}\left(\frac{T_{3, p}}{T_{1}}-1\right) \frac{\left(\frac{W_{p}}{W_{p}+W_{s}}\right)^{2}}{\left(\frac{d_{2}}{D}\right)^{4}} .
$$

This was evaluated and is plotted in figure 7 , c.

As it is considered that the pressure is uniform across station $3, p_{3, s}=p_{3, p}$ and $\left(p_{2}-p_{3}\right)_{s}$ may be determined as follows:

$$
\left(p_{2}-p_{3}\right)_{s}=\left(p_{1}-p_{2}\right)_{p}+\left(p_{2}-p_{3}\right)_{p}-\left(p_{1}-p_{2}\right)_{s} .
$$

All of the terms on the right side have been evaluated, and their sum is plotted in figure 7, c.

The magnitude of this pressure change is variable over the operating range, and the variation is accomplished by changing the opening of the adjustable throttle shown in figure 6 . The pressure change is expressed in terms of $q_{1}$, but it is also of interest to define the change of pressure with respect to $q_{2, s}$, as this may be of aid in the design of the throttle. Equation 9 is the relation between $q_{1}$ and $q_{2, s}$, and it may be applied for this purpose as follows:

$$
\frac{\Delta p_{s}}{q_{2, s}}=\frac{\left(p_{2}-p_{3}\right)_{s}}{q_{1}} \frac{q_{1}}{q_{2, s}}=\frac{\left(p_{2}-p_{3}\right)_{s}}{q_{1}}\left[\frac{1-\left(d_{2} / D\right)^{2}}{1-\left(d_{1} / D\right)^{2}}\right]^{2}
$$

This relation was evaluated and $\left(p_{2}-p_{3}\right)_{s} / q_{2, s}$ is plotted versus $T_{4} / T_{1}$ in figure 7 , d. When the throttle is opened, the fraction of air going into the primary zone decreases, thereby decreasing $T_{4} / T_{1}$. If the throttle were removed entirely $\left(\Delta p_{s}=0\right)$, $T_{4} / T_{1}$ would be about 1.8. Lower values of $T_{4} / T_{1}$ could only be achieved by decreasing $T_{3, p} / T_{1}$ or by insertion of a throttle in the primary zone.

Change of pressure due to mixing of the secondary and primary streams may be calculated by eq 19 to 22. The term $d_{3}$ in these equations for this case is equal to $D$, and when this substitution is made, $\left(p_{3}-p_{4}\right) / q_{1}$ can be evaluated. Figure 7 , e, is a plot of this quantity. The over-all change of pres- 
sure, $\left(p_{1}-p_{4}\right)$, which was evaluated by adding the successive changes, is plotted in figure $7, \mathrm{f}$.

Loss of total pressure may be determined by eq 23 . When $q_{4} / q_{1}$, expressed by eq 20 , is substituted in 23 the following relation is derived:

$$
\frac{\Delta p_{t}}{q_{1}}=\frac{p_{1}-p_{4}}{q_{1}}-\frac{T_{4}}{T_{1}}+1 .
$$

This was evaluated and is plotted versus $T_{4} / T_{1}$ in figure $7, \mathrm{~g}$. Inspection of this curve reveals that the loss is substantially higher than in the previous case at the higher values of $T_{4} / T_{1}$. The previous case was calculated on the basis that pressure was lost due to friction in the primary zone, but in this case none was assumed. In any practical application of a chamber of this type, some means of stabilizing the flame would be necessary, and this would introduce loss of pressure in the primary zone. The magnitude of the loss of pressure required in service probably would be comparable to that in the conventional chamber. If this loss had been considered, the over-all loss of total pressure would have been higher than indicated in figure $7, \mathrm{~g}$, and higher than that of the conventional chamber.

The ratio of the velocities of the primary and secondary streams at station $3, V_{3, p} / V_{3, s}$, was evaluated and is plotted in figure $7, \mathrm{~h}$. This ratio increases with $T_{4} / T_{1}$, and if this increase is a sign of an increase in the effectiveness of mixing, uniformity of temperature in the exhaust will be good in this chamber under conditions of maximum temperature rise.

The problem of control in combustion chambers of this type would be more difficult than that of a conventional chamber. A mechanism would be required to adjust the throttle in the secondary air in response to change of $T_{4}$ or to change of over-all airfuel ratio. Another method, analagous to that used in reciprocating engines, would be manual control of this throttle, with fuel rate automatically controlled in accordance with throttle opening. The problems of manufacture, installation, and maintenance would be more complicated, but improved performance over a wider range might compensate for the added mechanical complications.

\section{Experimental Program}

The specifications for the preceding analysis were chosen with the thought that experimental work would be undertaken to check the results of the analysis. It is relatively simple to match experiment and analysis insofar as the physical size of the chamber and temperature rise therein are concerned, but deviation in other respects probably would influence the results. The mere fact that combustion occurs requires addition of mass (of fuel) to the flowing stream. Specific heat is not independent of temperature, loss of pressure due to friction cannot be localized, and exchange of heat between primary and secondary streams before mixing cannot be prevented. Although uniform velocity can be provided across the plane of the chamber entrance in the ex- periments, the flow will take up a nonuniform distribution at other stations. Operation of the chamber at a finite velocity of flow would also introduce some deviation due to compressibility, but not of serious magnitude if the flow Mach number is not above 0.1. Influence of compressibility on the flow relations is discussed in detail in reference [3]. Some deviation between theory and experiment is to be expected, but probably is not of serious magnitude.

\subsection{Experimental Apparatus}

The experimental combustion chamber was constructed of standard 6 in. pipe with a 4 - $\mathrm{ft}$ coaxial liner, $3 \%$ in. inside diameter and a wall thickness of $1 / 16$ in. The pipe was cut and flanged as illustrated in figure 8 for accessibility to the liner. A schematic drawing of the system, in which the location of the stations is shown, is also presented in figure 8 . Dimension $\mathrm{X}$ was 10 in. in the experiments on flow and heat release, and $8 \mathrm{ft}$ in the experiments on mixing. Uniform velocity across the plane of the entrance to the chamber was provided by a nozzle of 12 -in. diameter at the inlet and 6 in. at the outlet, or chamber, end. Throttles were placed in the secondary or primary zones as required to control the air distribution between zones. The throttle in the secondary zone was made of two thin annuli containing equally spaced $7 / 8$-in. holes. Rotation of one annular plate with respect to the other controlled the opening and thereby the distribution. Throttles in the primary zone consisted of disks with various sized holes at their centers.

Flow of air to the chamber was metered by a calibrated orifice located in the system far upstream from the burner. Liquid propane flowed from a weighing tank through a rotameter to a vaporizer tube in the shape of a hairpin mounted in the system far downstream from the liner. Gaseous propane from the vaporizer flowed to the multihole fuel injector located in the liner about 6 in. downstream
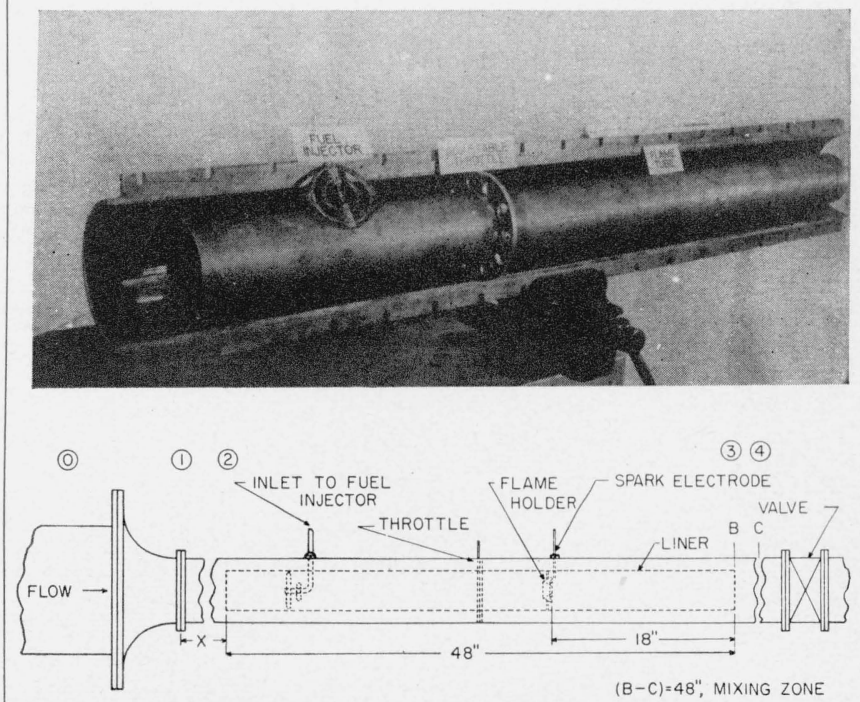

Figure 8. The experimental chamber. 
from station 2. The injector was made of three concentric but not coplanar rings of tubing manifolded together and drilled with numerous small holes. The injector shown in figure 8 was used only in the preliminary experiments and was made of two concentric rings. Mixing of the fuel with primary air took place between the injector and flame holder, and the flame was initiated by a spark at the flame holder. The spark was turned off after smooth combustion was established and the flame was stabilized at the flame holder. The flame holder was a ring of triangular cross section, $2 \frac{3}{8}-$ in . outside diameter and $1 \frac{1 / 8}{8}$-in. inside diameter. It was placed 18 in. upstream from the end of the liner (station 3). A water-cooled valve was placed at the outlet of the pipe system, and this was used to control the chamber pressure.

Initial attempts to operate the chamber were uniformly unsuccessful because of rough or intermittent combustion. Numerous changes in the primary zone and downstream portions of the system made no improvement whatsoever, and it was not until an orifice plate was installed $5 \mathrm{ft}$ upstream from the nozzle that smooth combustion was possible. This orifice plate was replaced by one perforated with numerous smaller holes, and all experiments reported herein were made with this plate in the system. It is probable that this improvement was due to change of the effective length of the column of gas in the system.

Instrumentation was added for the measurements of temperature, pressure, and flow in the chamber. Total-pressure tubes were installed at stations 1 and 2 p. A pitot-static tube was also used at station $2 p$. Static-pressure wall taps were located at stations $0,1,2 \mathrm{p}, 2 \mathrm{~s}, 3 \mathrm{~s}, 3 \mathrm{p}$, and 4 . Temperature was measured at station 0 and also at a point far downstream from station 4 by silver-shielded Chromel-Alumel thermocouples. The pipe system contained two right-angle bends beyond station 4 to insure that the gas was well mixed by the time it reached the last thermo. couples. The reading of this thermocouple was considered the average temperature of the exhaust gas, $T_{4}$. Some tests were conducted with insulation around the pipe beyond station 3 to determine the magnitude of the heat loss from the system. Temperatures in the system were high, and the pipe was not insulated in the majority of tests because of possible damage to the system by the prevailing high temperature.

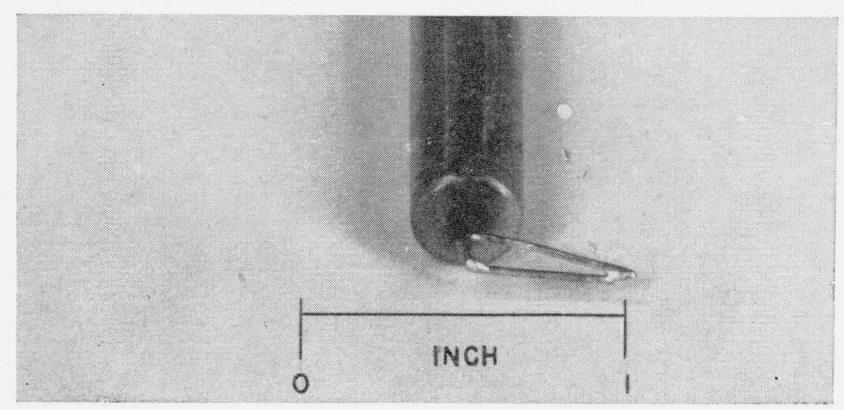

FIGURE 9. Iridium-iridium-rhodium thermocouple.
In the experiments in which mixing of primary and secondary streams was studied, most of the above instrumentation was removed to prevent interference with the flow distribution in the chamber. Considerable trouble with asymmetrical flow conditions in the mixing zone was experienced, and it was necessary to rebuild the system on this account. The wall thickness of the liner was increased to $3 / 32$ in., and the liner was mounted coaxially in a $21-\mathrm{ft}$ length of 6 -in. pipe. Dimension $X$, figure 8 , in these experiments was $8 \mathrm{ft}$. Elimination of flanged joints in the vicinity of the liner by this means made substantial improvement in the mixing zone. The liner of heavier construction warped less, and this also probably helped to improve the conditions for the mixing study.

Instrumentation in the mixing zone of the chamber consisted of water-cooled total-pressure tubes, bare Chromel-Alumel thermocouples of 22-gage wire, and iridium - 50 percent iridium, 50 percent rhodium (Ir-IrRh) thermocouples of about 20-gage wire. Three of the Chromel-Alumel thermocouples were driven by electric motors to traverse the pipe at a speed of $2 \mathrm{in} . / \mathrm{min}$. This was equal to the chart speed of the temperature recorder, and by this means a full-scale profile of temperature was obtained. One motorized couple was located $32 \mathrm{in}$. and 2 were 48 in. from station 3 and at right angles to each other. Other Chromel-Alumel thermocouples were hand operated, and were located in the mixing zone between the motorized couples.

In order to measure the higher temperatures in the mixing zone, Ir-IrRh thermocouples [4] in watercooled supports were used. One of these thermocouples with its support tube is shown in figure 9. In this instance the wires are bent at right angles to the tube in an effort to gain depth of immersion in the gas. Only one bent couple was used, others projected straight into the stream at least $5 / 16$ in. These Ir-IrRh couples were operated by hand and were used in the first $32 \mathrm{in}$. of the mixing zone.

\subsection{Experimental Procedure and Results}

The burner was ignited at an air velocity at station 1 of about $20 \mathrm{ft} / \mathrm{sec}$, and after smooth combustion was established, the rates of air and fuel were increased simultaneously until the velocity at station 1 was about $60 \mathrm{ft} / \mathrm{sec}$. Measured temperature at station 4 was maintained nearly constant during this operation because this would indicate nearly constant fuel-air ratio in the primary zone (at a given throttle opening). Injection of the propane vapor through the multihole injector provided nearly homogeneous mixtures of air and fuel. Limits of smooth combustion in homogeneous mixtures are narrow, and the method of control was useful in keeping within the limits while changing conditions in the burner. After the burner was brought near the desired operating condition, final adjustments were made of fuel and air rates and burner pressure level. The fuel was adjusted until the burner sounded smoothest. This criterion did not necessarily guarantee the same fuel-air ratio in the primary 
zone in all tests, but it was adopted because operation otherwise (under conditions of resonant combustion) would affect adversely the accuracy of the measurements of flow and pressures. Although resonance was not eliminated completely, the data indicate that its effects were reduced to a tolerable magnitude.

Because the primary zone was operated at nearly constant mixture ratio, the desired range of conditions of over-all temperature rise was attained through the use of throttles.

The rate of air flow was about $1.25 \mathrm{lb} / \mathrm{sec}$ in the majority of tests. Temperature of the air varied from $560^{\circ}$ to $610^{\circ} \mathrm{R}$, and pressure generally was about 1.5 atmospheres absolute. Some variation from these conditions was tried but with no effect on the results.

Dynamic pressure, $q_{1}$, at the inlet to the chamber under these conditions of flow was about $1.2 \mathrm{in}$. of water. Temperature ratio in the primary zone $T_{3, p} / T_{1}$, was calculated to be in the range of 6.6 to 7.1 , for mixtures of 0.06 part of gaseous propane and 1 part of air by weight over the range of values of $T_{1}$ mentioned.

Experimental work on the chamber was divided into two parts, one in which problems of flow and heat release were studied and the other in which mixing of primary and secondary streams was studied. Results of the former will be described first.

\section{a. Experiments in Flow and Heat Release}

As mentioned before, fuel rate was adjusted in these experiments until combustion was smoothest, and consequently the fuel-air ratio in the primary zone was not constant in all tests. Tests in which the metered fuel-air ratio was $0.06 \pm .005$ were selected, and the results of these tests are reported herein. Selection by this rule reduced the spread of the data somewhat and did not change the basic relations.

Values of measured average temperature $\left(T_{4}\right)$ after mixing of the gases by passage around two bends in the system indicated either low combustion efficiency (85 to 90 percent) or large heat losses. Analyses of the mixed outlet gas in three tests by a gravimetric method [5] indicated a combustion efficiency of 98 percent, while a heat balance based on $T_{4}$ and the assumption of an adiabatic system indicated efficiency of about 90 percent. When insulation was installed around the pipe beyond station 3, efficiency based on $T_{4}$ ranged between 92 and 100 percent, and it was concluded that loss of heat from the system when uninsulated was large. Prevailing temperatures in the system were high, and it appeared advisable to operate without insulation for reasons of safety. On the assumption that the low values of efficiency were caused by heat loss and not by poor combustion, data in this report are based on temperature $T_{4}$ calculated on the basis of 100-percent combustion of the mixture of total air and fuel. Cool secondary air contacted the walls of the 6 -in. pipe down to and somewhat beyond station 3, and it is expected that loss of heat from the gas down to station 3 and somewhat bevond would have been negligible. The majority of the observations were made in this upper section of the burner, and this is considered a justification for ignoring the heat loss.

Results of the tests are presented graphically in figure 10 , and results of the last analysis (fig. 7) are included for comparison. The portion of the air
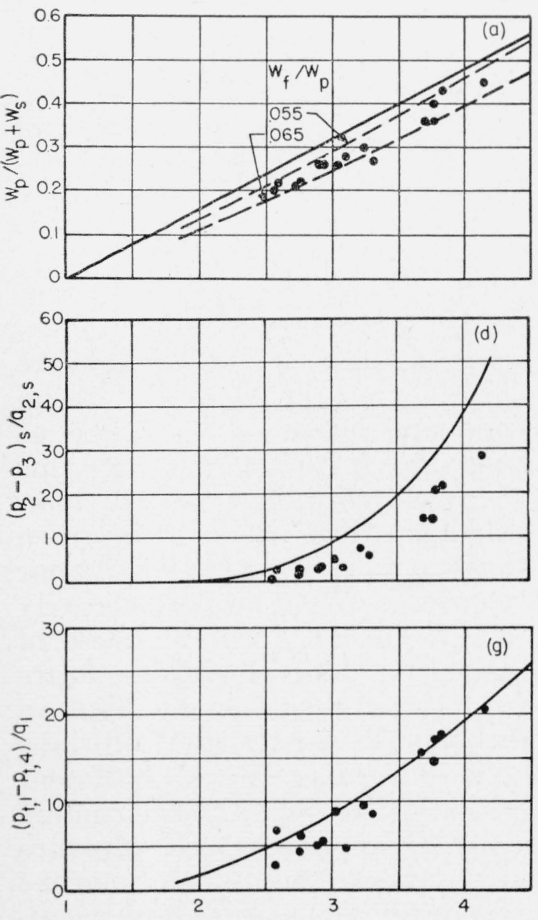
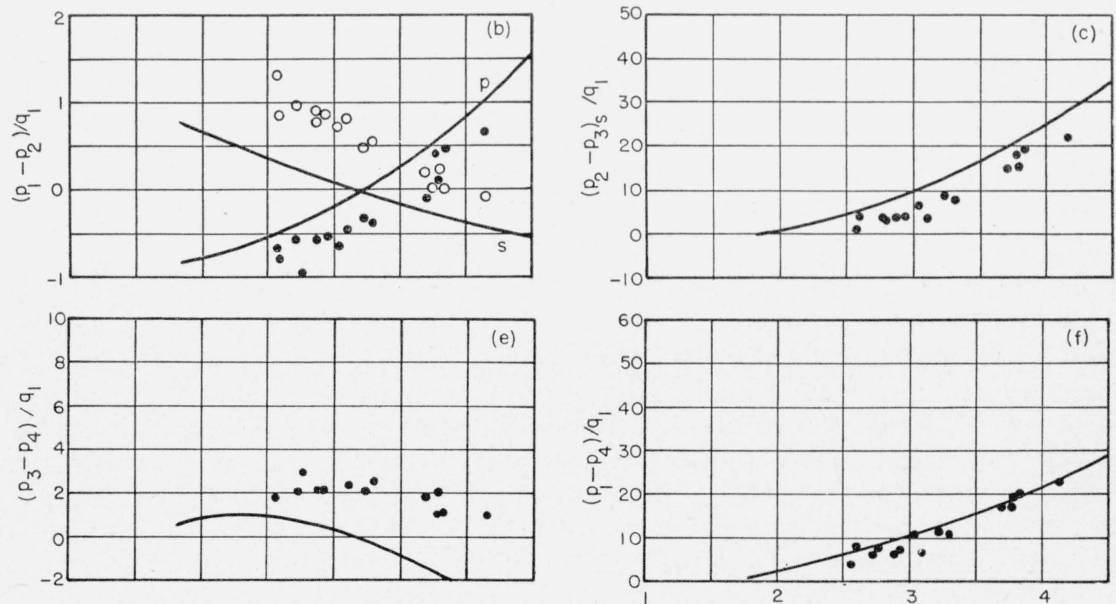

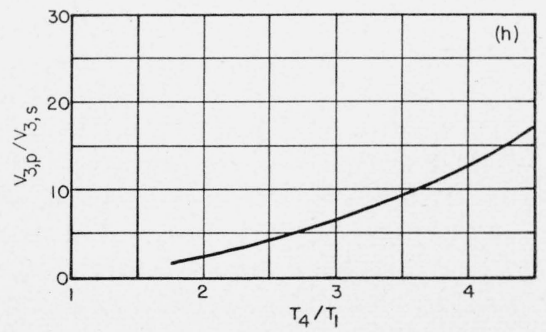

Figure 10. Results in the experimental chamber 


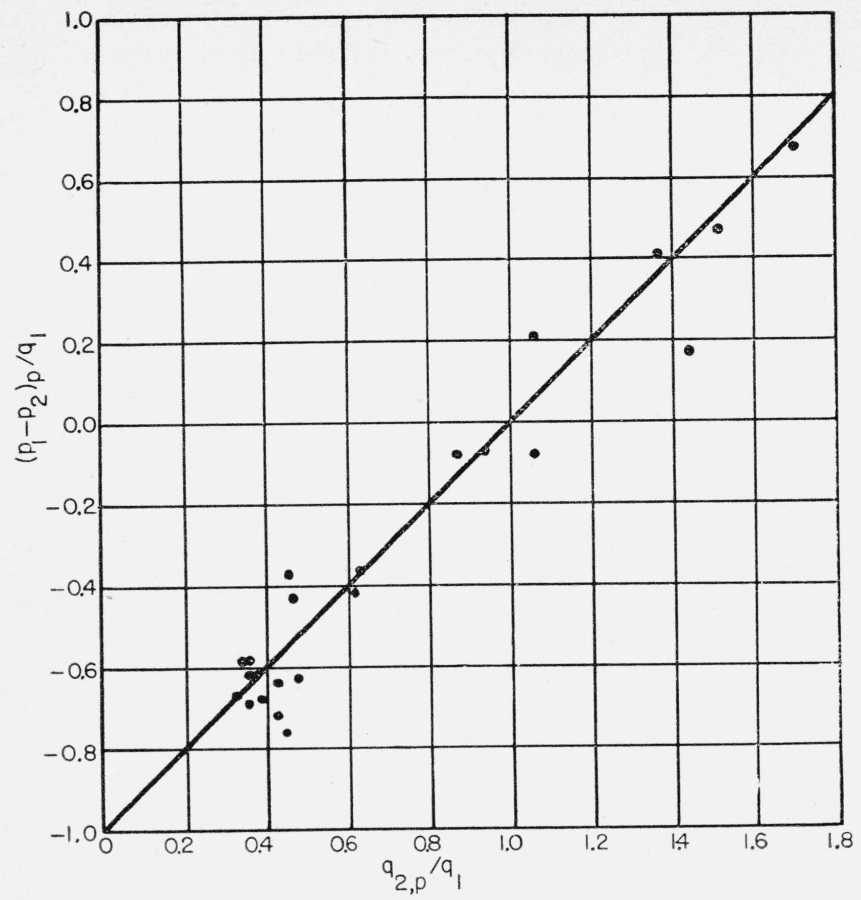

Figure 11. Static and dynamic pressure changes in the primary stream.

that entered the primary zone, figure 10 , a, was determined from pressure $q_{2, p}$ given by a pitot-static tube at station $2 p$ in the primary zone, or by the difference of pressure from a total head tube and static pressure wall tap. The data are displaced from the theoretical curve, but compare well with curves based on known combustion characteristics of propane-air mixtures. These curves were calculated for fuel-air mixtures of 0.055 and 0.065 in the primary zone, which is the range in the tests reported. These curves take into account the variation of specific heat with temperature and the added mass of fuel.

Division of the air into primary and secondary streams between stations 1 and 2 is accompanied by pressure changes, and results of measurements of these are presented in figure $10, \mathrm{~b}$. The data are again displaced from the theoretical curve, but the same general relationship as predicted by Bernoulli's equation is evident. Some of the displacement is for reasons enumerated above. A comparison of the measured data for the primary stream with the curve calculated from eq 1 is presented in figure 11, where the line represents the equation. In general it appears that the equation is applicable. Because magnitudes of the pressures are small, and any effect of resonant combustion in the chamber on the measurements would be large on a percentage basis, it is difficult to decide which of the readings are correct. Several chemical analyses of the exhaust gas at station $3 p$ were made, and the fuel-air ratios calculated from these analyses were in good agreement with those calculated from values of $q_{2, p}$ derived from eq 1 and the observed value of $\left(p_{1}-p_{2}\right)_{p} / q_{1}$. This is not regarded as conclusive evidence that measured

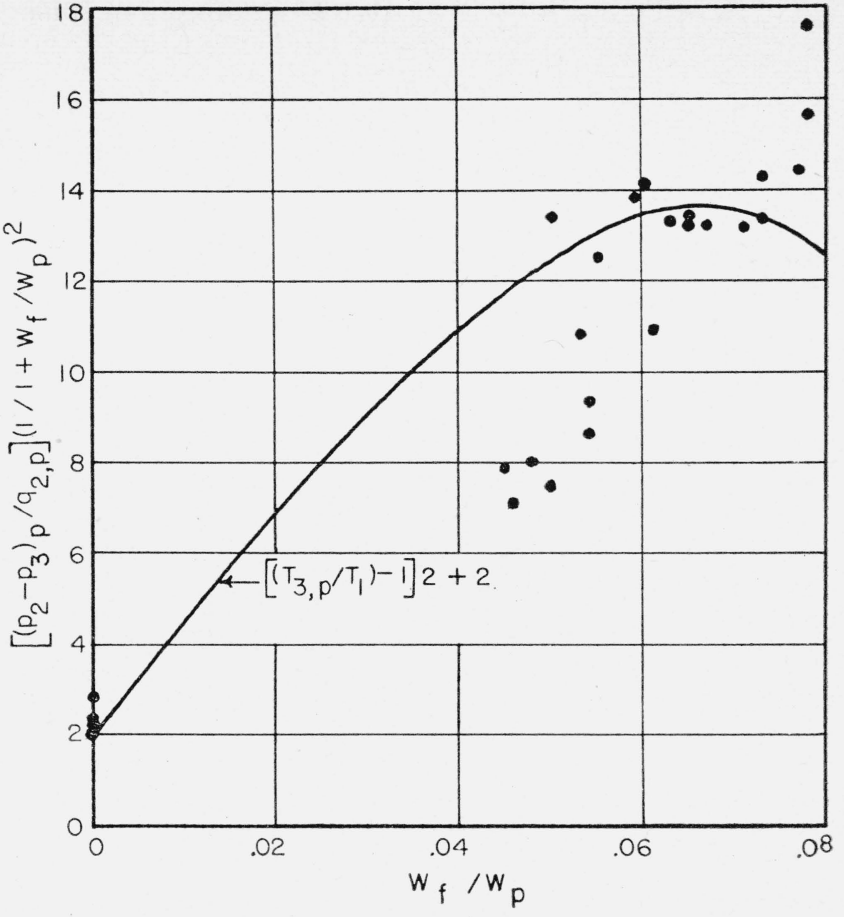

Figure 12. Pressure drop in the primary zone.

values of $\left(p_{1}-p_{2}\right)_{p}$ were always correct. These chemical analyses also indicated essentially complete combustion (based on oxygen consumed) across station $3 \mathrm{p}$, and it was concluded that the flame holder was not too close to station 3.

Change of pressure between stations 2 and 3 in the secondary zone is plotted in figures $10, \mathrm{c}$, and $10, \mathrm{~d}$, and the data, although displaced from the theoretical curves, are in good agreement with the theory. Pressures between these two stations were also measured in the primary zone, and these are compared to those predicted by the conservation of momentum equation in figure 12. In this figure observed values of $\left(p_{2}-p_{3}\right)_{p} / q_{2}, p$ were plotted versus fuel-air ratio in the primary zone, and the theoretical curve is based on calculated values of flame temperatures of propaneair mixtures. Velocity, and therefore dynamic pressure, in the primary zone is increased by the addition of fuel to the air stream, and observed $q_{2, p}$ was corrected as indicated in the figure to account for this. Observed pressures were not corrected for the momentum of the fuel, which in these experiments was injected downstream with a pressure drop in the injector of from 20 to $60 \mathrm{lb} / \mathrm{in}^{2}{ }^{2}$. With no burning, observed pressure drop was about $2 q_{2, p}$, which is due to friction in the primary zone. This value of $2 q_{2, p}$ was added to the theoretical to account for the friction drop. In the neighborhood of fuel-air ratio of 0.06 , observed pressure drop is in good agreement with the theoretical, but at lean condition the observed values are low. The reason for the low observed values is not clear, but it could be either incomplete combustion in the primary zone or an effect of resonance. If combustion were not complete in the primary zone, 
it did go to completion between stations 3 and 4 because observed values of $T_{4}$ indicated normal combustion efficiency.

One of the basic assumptions in the analysis of the flow in the combustion chamber was that pressure was uniform across the plane of station 3 . Some deviation from this condition was observed; it was found that pressure of the secondary stream exceeded that of the primary stream by about $0.1 q_{3, p}$ in most cases, and by as much as $0.3 q_{3, p}$ in some. However, conditions at the static pressure wall tap may have been affected adversely by warping and scale formation caused by the high temperature of the liner. In any event it appears that the pressure differences are not large enough to detract from the value of the analysis on the basis of equal pressure. A strong flow of the secondary air into the primary jet is indicated by the surplus of pressure in the secondary stream.

Mixing of the two streams takes place beyond station 3, and the observed pressure changes between stations 3 and 4 are plotted in figure 10,e. Comparison with the theoretical indicates that the observed pressure changes are large, probably because of wall friction and turbulence caused by the velocity difference between the primary and secondary streams. Measurement of the friction drop with no burning indicated it to be about 25 percent of the dynamic pressure of the stream, which is a normal loss for this length of 6 in. pipe. During burning, average conditions of flow across the mixing section would give a dynamic pressure equal to $q_{1} T_{4} / T_{1}$, and hence the wall-friction drop on this basis would be equal to $0.25\left(T_{4} / T_{1}\right) q_{1}$. If the data at the condition $T_{4} / T_{1}=4$ is used as an example, the observed $\left(p_{3}-p_{4}\right) / q_{1}$ was about 1 , and correction by the friction drop $\left(\Delta p / q_{1}=\right.$ $0.25 T_{4} / T_{1}=1$ ) would lead to $\left(p_{3}-p_{4}\right) / q_{1}=0$, which is to be compared to the theoretical value of -2 . The difference is probably due to high level of turbulence in the mixing streams.

Over-all loss of pressure in the experimental chamber is plotted in figure $10, \mathrm{~g}$, and compares well with the calculated values.

\section{b. Experiments in Mixing}

The combustion chamber was operated over a range of values of $T_{4} / T_{1}$ of from 1.5 to about 4 by changing the size of the throttle and its position. Corresponding values of the velocity ratio, $V_{3, s} / V_{3, p}$, were 1.5 to about 0.1 . The mixture in the primary zone was adjusted until it was on the lean side of stoichiometric by observation of the flame temperature while decreasing the fuel rate from the condition of excessive richness. Observations of temperature were made in the mixing zone after the lean condition was established to reduce effects of reaction of the flame gas with secondary air during mixing. Only one measuring instrument was used at a time to avoid disturbance of the flow.

Accuracy of the temperature measurements of the hot gases was not of a high order, because only a rough calibration of the $\operatorname{Ir}-\operatorname{IrRh}$ thermocouple was available, and because corrections to the indicated temperature were large. At high temperature, heat lost by radiation is large, and consequently the junction would be at a temperature lower than that of the gas. Corrections were calculated by a method that is based on the assumption that the heat lost from the thermocouple by radiation is equal to that gained by forced convection. The equation by which the corrections were determined is

$$
T_{\text {oas }}-T_{i}=\frac{h_{\text {rad. }} \epsilon}{h_{\text {conv. }}}\left(T_{i}^{4}-T_{\text {wall }}^{4}\right)
$$

$T_{i}$ is the temperature indicated by the thermocouple, $T_{\text {wall }}$ was assumed equal to the gas temperature next to the wall of the pipe, $h_{\text {rad }}$ is Stefan's radiation constant $\left(1.7 \times 10^{-9} \mathrm{Btu} / \mathrm{ft}^{2} /{ }^{\circ} \mathrm{R}^{4} \mathrm{hr}\right), h_{\text {conv. }}$. is the coefficient of convective heat transfer. For bare thermocouples, $h_{\text {conv. }}=225 \sqrt{G / 6} \mathrm{Btu} / \mathrm{ft}^{2} /{ }^{\circ} \mathrm{R} \mathrm{hr}$, which is an empirical relation to take into account the effect of mass rate of flow $G$ expressed in pounds per square foot per second. A quick determination of the emissivity, $\boldsymbol{\epsilon}$, of the Ir-IrRh thermocouples indicated it to be 0.26 , and $\epsilon$ for the Chromel-Alumel thermocouples was considered to be 0.9 .

As an example of temperature arrived at by this means, temperature of the flame gas at station 3 , $T_{3, p}$, in 13 tests averaged $4,350{ }^{\circ} \mathrm{R}$ with a root mean square deviation of $140^{\circ} \mathrm{F}$. This average temperature is about $300^{\circ} \mathrm{F}$ greater than the calculated flame temperature of a propane and air mixture near stoichiometric condition. It is not known whether the calculated corrections were too large or whether the calibration of the thermocouple is responsible for the difference. Some of the deviation mentioned was probably caused by inability to maintain the same fuel-air ratio in all tests.

Some measurements of dynamic pressure were also made in the mixing zone, and velocity was calculated from these measurements and observed temperatures and static pressures.

In the description of the experimental results that follows, the data were correlated with the ratio of velocity of the secondary to primary stream, $V_{3, s} / V_{3, p}$. The values of this ratio reported were estimated from the observed rate of fuel injection (on the assumption of a constant fuel-air ratio of 0.062 in the primary zone) and the observed temperature and pressure in the chamber. The difference between these estimates and some measurements was not larger than 10 percent. Because the velocity measurements were not considered accurate, the estimated values were accepted as adequate for the present purpose.

1. Axial Distribution of Temperature. Mixing of the primary flame gas and secondary air takes place in a system bounded by the walls of the 6-in. pipe, and the gas will approach an average or mixed temperature $T_{4}$ as it travels downstream from station 3 . Temperature at the axis of the burner, $T_{r=0}$, was expressed in the dimensionless form $\left(T_{r=0}-T_{4}\right) /$ $\left(T_{3, p}-T_{4}\right)$ and correlated with distance $x$ from station 3 by an empirical equation similar to that derived by 
Pai [6] for two-dimensional jet mixing. The equation involved the probability integral, as follows:

$$
\frac{T_{r=0}-T_{4}}{T_{3, p}-T_{4}}=\frac{2}{\sqrt{\pi}} \int_{0}^{z=f(x)} e^{-z^{2}} d z
$$

The first member of eq 45 represents experimental observations (at various values of $x$ ), and values of $z$ were selected to make the two members of the equation equal.

In these experiments it was not possible to make accurate measurements of $T_{4}$, because both velocity and temperature gradients existed in the stream, and no bends were used in the system to mix the gas. Previous experiments in which mixed temperature, $T_{4}$, was measured, indicated relatively large heat loss from the system. These measurements were made downstream of the mixing zone, and if these were used as a guide to establish $T_{4}$ in the present experiments, $T_{4}$ by this method would probably be lower than the true value at station 4 . Calculation of $T_{4}$ on the assumption of 100-percent combustion efficiency, and no heat loss would give high values. Both methods were used to establish values of $T_{4}$, and although some difference was noted, the correlation obtained was not basically changed. The wall of the pipe was relatively cool in the first half of the mixing section, and it seemed logical to conclude that $T_{4}$, based on 100-percent combustion and no heat loss, was nearer the true value, and this value of $T_{4}$ was used in the correlation to be described.

Values of $z$ in eq 45 were determined from the observed axial temperature at various values of $x$, and these values of $z$ were plotted against the corresponding values of $x$. It was found that plots of log $z$ against $x / r_{3, p}$, where $r_{3, p}$ is the radius of the liner, could be represented by straight lines. Plots of this kind are shown in figure 13 for three different condi- tions of $V_{3, s} / V_{3, p}<1$. The three lines have the common point $z=1.5, x / r_{3, p}=9$, and therefore a general equation can be written

$$
\ln z=-c x / r_{3, p}+k,
$$

where $k$ is a constant, and $c$ is the slope of the lines. When $V_{3, / s} V_{3, p}>1$, the same relationship was observed, but only two out of five tests gave plots that passed through the common point.

A Maclaurin expansion of the probability integral would indicate that $\left(T_{r=0}-T_{4}\right) /\left(T_{3, p}-T_{4}\right)=z$ to a first approximation. This approximation is good when $z \leq 0.7$, and in this range temperature can be approximated by

$$
\frac{T_{r=0}-T_{4}}{T_{3, p}-T_{4}} \simeq z=k e^{-c x / r_{3, p}},
$$

and differentiation of this would lead to

$$
\frac{d\left[\frac{T_{r=0}-T_{4}}{T_{3, p}-T_{4}}\right]}{d x} \simeq-c \frac{T_{r=0}-T_{4}}{T_{3, p}-T_{4}},
$$

and from this it appears that $c$ is a measure of the effectiveness of the mixing in bringing the temperature at the axis to the mixed temperature $T_{4}$.

Slope $c$ was correlated with $T_{3, s} / T_{3, p}$ in figure 14 , and the data suggest a parabolic relationship, with $c$ a minimum at a velocity ratio of unity

These results have been presented thus far without reference to or comparison with the theory of mixing of jets. The mixing of streams, different in both temperature and velocity, has received very limited attention, and consequently the present results will be compared with the theory for incompressible flow presented in reference [2] and utilized in a previous
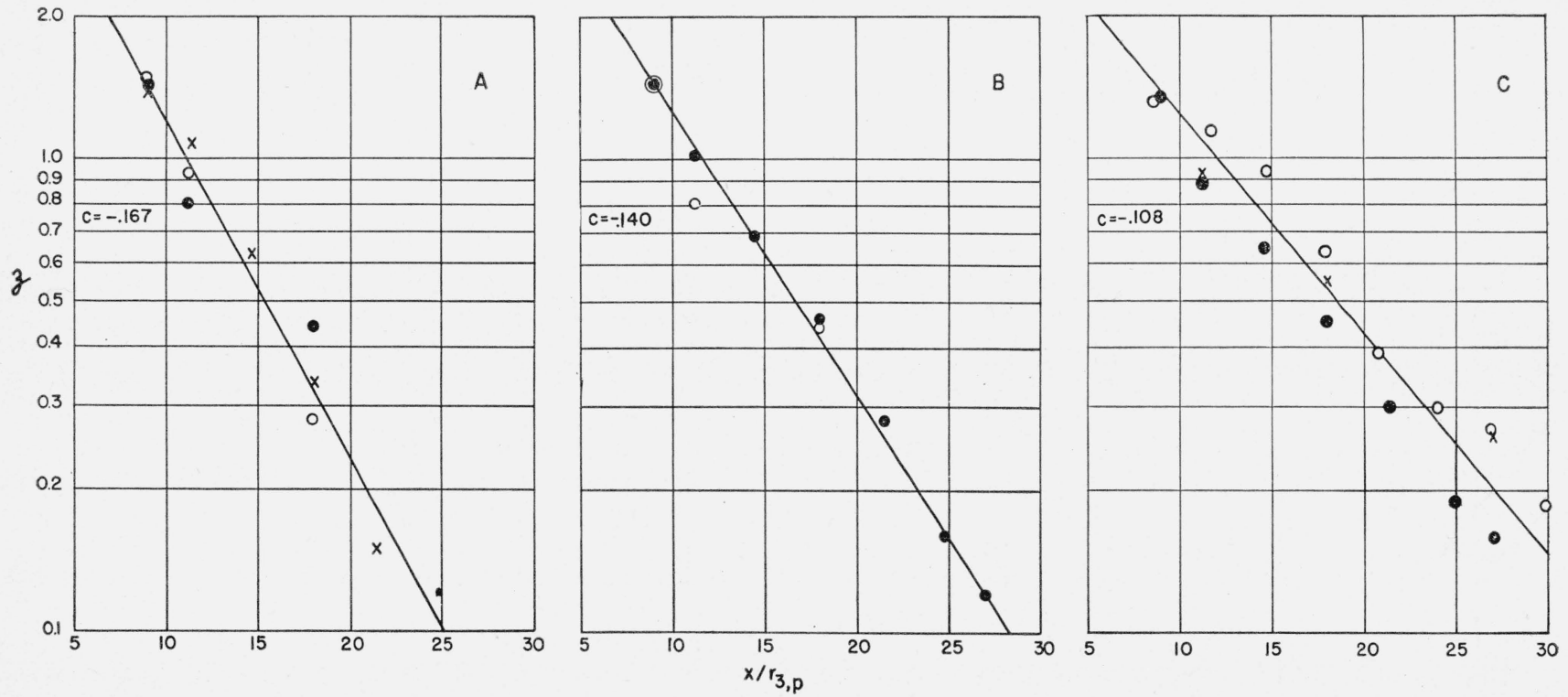

FIgURE 13. Correlation of axial temperature with distance by the probability integral.

(A) $V_{3,8} / V_{3, p}=0.12 ; T_{4} / T_{1}=3.8$. (B) $V_{3, s} / V_{s, p}=0.17 ; T_{4} / T_{1}=3.3$. (C) $V_{3,8} / V_{3, p}=0.38 ; T_{4} / T_{1}=2.3$. 
section of this report. A comparison will be presented also with the recently presented experimental results of Forstall and Shapiro [7] obtained in the study of coaxial streams at a common temperature. It is expected that differences shown by the comparisons would be caused by the large difference of Temperature or density between the streams in the present experiments. Hereinafter, comparison with the work of Squire and Trouncer [2] is referred to as a comparison with the theory, and the results of Forstall and Shapiro are referred to as the "other experi ments."

Figure 15 is a comparison of the characteristics of the mixing as observed along the axis of the burner with the theory and also with the other experiments. Because a jet in a general stream would mix and eventually approach the properties of the stream, the dimensionless fractions of temperature (and velocity) contain the temperature (and velocity) of the secondary stream in order to make the comparison. In general, it may be said that in the median range, temperature expressed this way varies inversely with axial distance, and this is in agreement with the other experiments but not with the theory.

At the condition of $V_{3, s} / V_{3, p}=0.375$, limited information about axial velocity in the mixing zone indicates that it is transferred at a slower rate than temperature. Three other tests at the condition $\mathrm{V}_{3, s} / V_{3, p}=0.25$ also indicated this. Comparison of the data on velocity with the other experimental results indicates a somewhat slower rate of transfer in the present experiments.

When $V_{3, s} / V_{3, p}$ was 0.125 , the data show that transfer of temperature in the present experiments approximates that of velocity in the other experiments. However, in the expectation that velocity would be transferred in this case also at a slower rate than temperature, it appears that the rate of transfer is less in the present experiments than in the other experiments. One set of data points in this figure was for the condition $V_{3, s} / V_{3, p}=0.18$, and this was

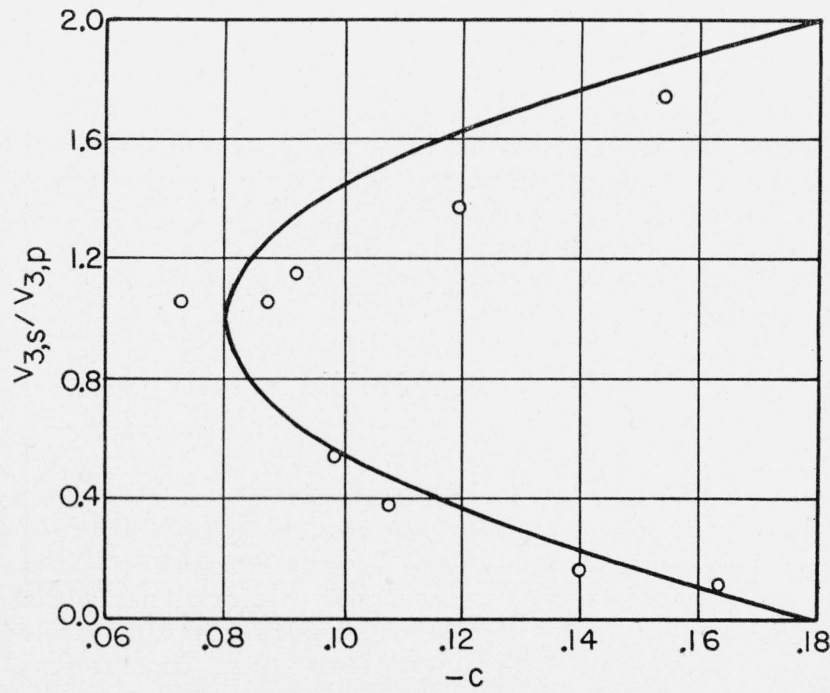

FIGURE 14. Effectiveness of mixing. included because it illustrates more clearly the inverse relationship of temperature and distance. In this system temperature approaches $T_{4}$ as mixing becomes complete, not $T_{1}$, and the completely mixed condition would be attained when $\left(T_{r=0}-T_{1}\right) /$ $\left(T_{3, p}-T_{1}\right)=\left(T_{4}-T_{1}\right) /\left(T_{3, p}-T_{1}\right)$. The latter fraction is 0.47 when $V_{3, s} / V_{3, p}=0.125$, and the $x$ data points show the beginning of a slower approach of temperature (at the lower values) to the mixed condition. At $V_{3, s} / V_{3, p}=0.18$, the fraction was 0.33 , and the slower approach to the mixed condition occurred downstream from the place where the observations were made in this case.

It will be noted that the straight lines were extended to a value of unity for the temperature fraction, and at both conditions of $V_{3, s} / V_{3, p}<1$ the axial distance is about $11 r_{3, p}$. This same value of $11 r_{3, p}$ was noted when $V_{3, s} / V_{3, p}$ was 0.55 , which leads to the conclusion that the burner can be assigned a characteristic length. The general inverse relationship of temperature and axial distance, and the characteristic length, would be of general utility in making an approximation of the temperature field. In the theory the extent of the potential core of velocity is variable, whereas in the present experi-

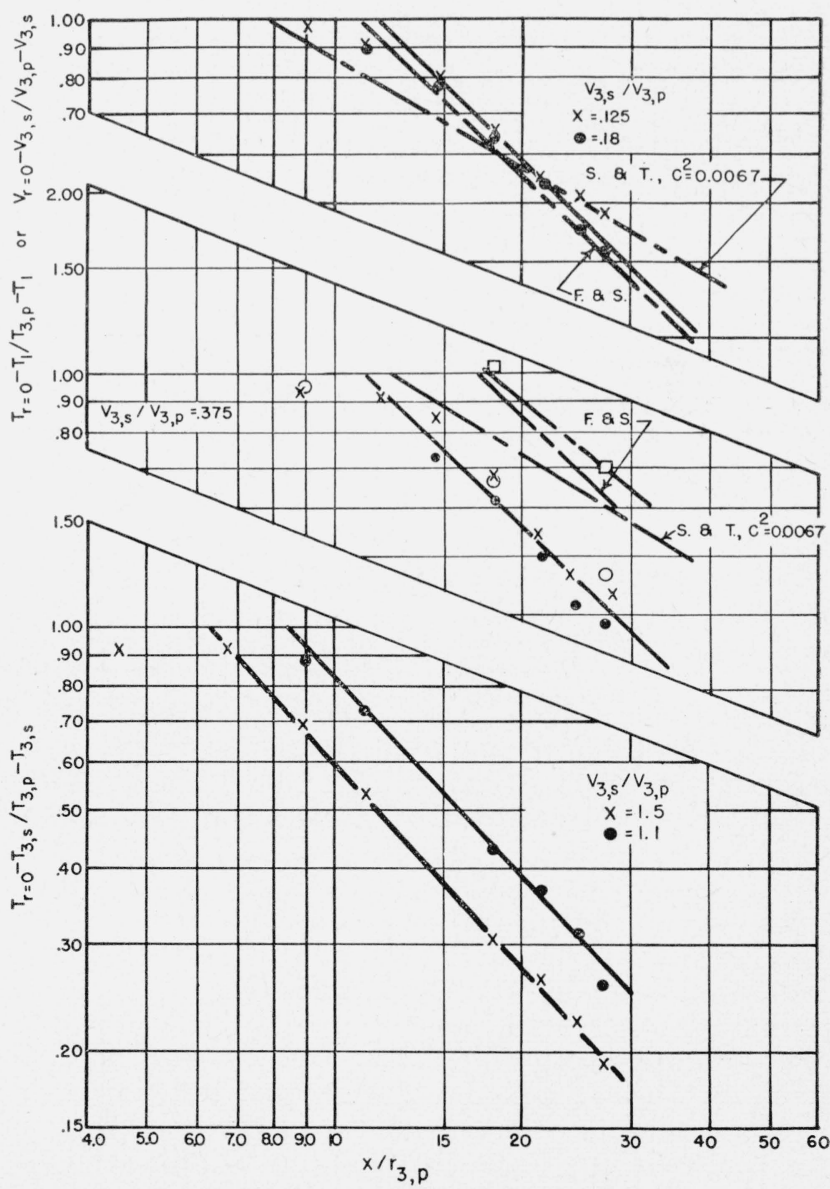

FIGURE 15. Axial temperature and velocity distribution. _- Temperature; _- - , velocity. 

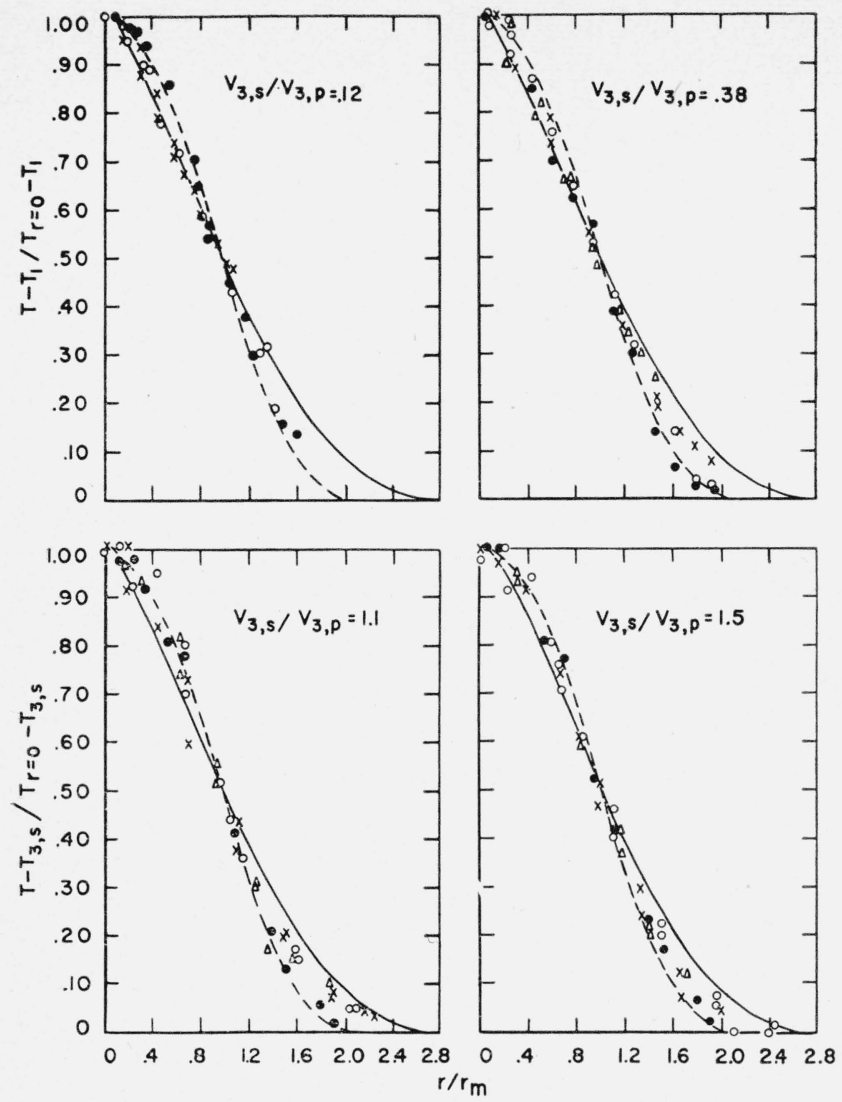

Figure 16. Lateral temperature profile.

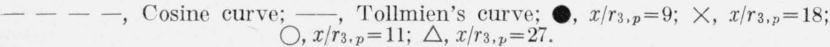

ments it appears that the extent of the potential core of temperature (for purposes of approximation) can be regarded as constant.

Data at the conditions of $V_{3, s} / V_{3, p}>1$ are also included in figure 15, but comparison is not possible because this condition is not investigated in references [2 and 7]. The same inverse relationship is evident, but here there appears to be no evidence of a characteristic length.

2. Lateral Distribution of Temperature. Numerous traverses of temperature were made in the mixing zone of the chamber to investigate the lateral spread of temperature in the two coaxial streams. The generalized profiles were compared with that of the cosine curve as assumed by Squire and Trouncer in [2], and with that calculated by Tollmien [1] for a free, round, incompressible jet. Tollmien also used the momentum transfer theory and assumed that mixing length was proportional to the width of the mixing region. However, the calculations were based on the assumption of a point source, and therefore in practice similarity of profile would not be reached until axial distance became large compared to jet size.

Four profiles of temperature are presented in figure 16 to illustrate the shape over the range of operating conditions. In some of the runs, temperature of the secondary air, $T_{3, s}$, was measured just before the point of mixing, and, as expected it was somewhat higher than the inlet temperature $T_{1}$ because of heat transfer from the primary zone. Two profiles of temperature in figure 16 were calculated by using these measured values of $T_{3, s}$. Effect of this change to $T_{3, s}$ was a slight shift of the data points to lesser values of the temperature fraction and to greater values of the radius fraction.

At high relative velocity of the primary stream, the edge of the mixing region intersects the wall of the 6 -in. pipe in which mixing takes place at relatively small values of axial distance, and consequently the profiles are not complete. Also, the mixing downstream of the point of intersection is no longer in free streams, and the validity of comparison with mixing in free streams is questionable. However, some information can be gained by a comparison, and it is presented with this limitation in mind.

At an axial distance of $9 r_{3, p}$, the profile of temperature is in good agreement with the cosine curve, but at greater distances there is a tendency to approach the distribution predicted by Tollmien. The experimental velocity profiles of Forstall and Shapiro were a good match with the cosine curve at all distances studied. Ratio of velocity of secondary to primary streams does not affect the shape of the temperature profile.

Although the shape of the profile tends to change with axial distance, the magnitude of the radius of half temperature $r_{m}$ is a good indication of the width of the mixing region and is plotted versus axial distance in figure 17. Theoretical results of Squire and Trouncer for velocity are included for comparison. Experimental findings of Forstall and Shapiro agreed well with the theory and are therefore not included in the figure.

At the condition $V_{3 s} / V_{3, p}=.125, \quad r_{m}$ increases slowly in the region of the potential core, which in this case extends downstream a distance of $11 r_{3, p}$, compared to about $8 r_{3, p}$ in the theory. It is to be noted that at the end of the potential core of temperature $r_{m}$ is $1.1 r_{3, p}$, and therefore the width of the mixing region would be about $2.2 r_{3, p}$ if it were not cut off by the 6 -in. pipe (width $=1.7 r_{3, p}$ ). Beyond the potential core the experimental data are not as consistent, but it may be said that $r_{m}$ grows approximately as predicted in the theory. With respect to the two points of largest $r_{m}$, these also are nominally beyond the wall of the 6-in. pipe. However, in these instances the center line of the profile was off the center of the pipe enough to measure these radii on one side of the traverse. This asymmetry has been one of the major troubles in these experiments. Unknown changes in the configuration of the burner, possibly due to high prevailing temperatures, cause asymmetry and shifts of the center lines of the traverse. If the curve as drawn represents the data, then the constant of proportionality $C$ in the analysis would have to be less than 0.0067 by about one-third to bring the theoretical results in agreement with the present experiments. The rate of mixing on this basis is correspondingly lower than in the theory and in the other experiments. 

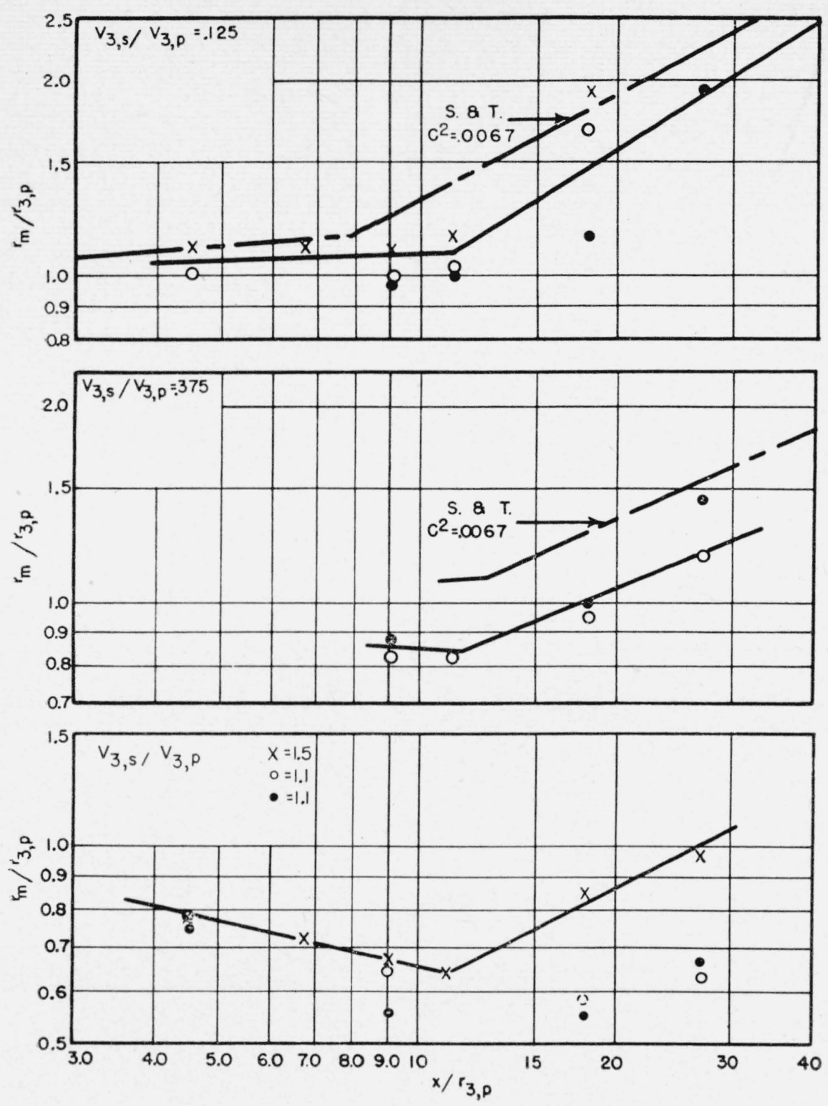

FIGURE 17. Half-boundary of mixing. , Temperature; - - - velocity.

At the condition $V_{3, s} / V_{3, p}=.375$, the extent of the potential core is also about $11 r_{3, p}$, but $r_{m}$ converges to a value of about $0.85 r_{3}, p$. At this point the mixing region extends to the wall of the pipe $\left(1.7 r_{3}, p\right)$ and therefore mixing downstream is influenced by the pipe. In this downstream region, $r_{m}$ diverges approximately as predicted by theory but again at greater values of axial distance. Radius of half maximum velocity was compared to that of temperature in three runs and was less by about 5 percent, which confirms the conclusion that temperature is transferred at a greater rate than velocity.

Data are also included in figure 17 on the radius of half maximum temperature when velocity of the primary stream was low compared to the secondary stream $\left(V_{3, s} / V_{3, p}=1.1\right.$ and 1.5$)$. Convergence in the region of the potential core is pronounced, and divergence begins again at an axial distance of about $11 r_{3, p}$. In all three cases in figure 17, divergence begins at an axial distance of about $11 r_{3, p}$, and this is considered additional evidence that the chamber has a characteristic length.

Two runs in which $V_{3, s} / V_{3, p}$ was 1.1 were made to show the effect of velocity difference between the primary and secondary streams, and data from these tests are also included in figure 17. Curves were not drawn through the data points in these two runs in which the mass rate of flow differed by 65 percent.

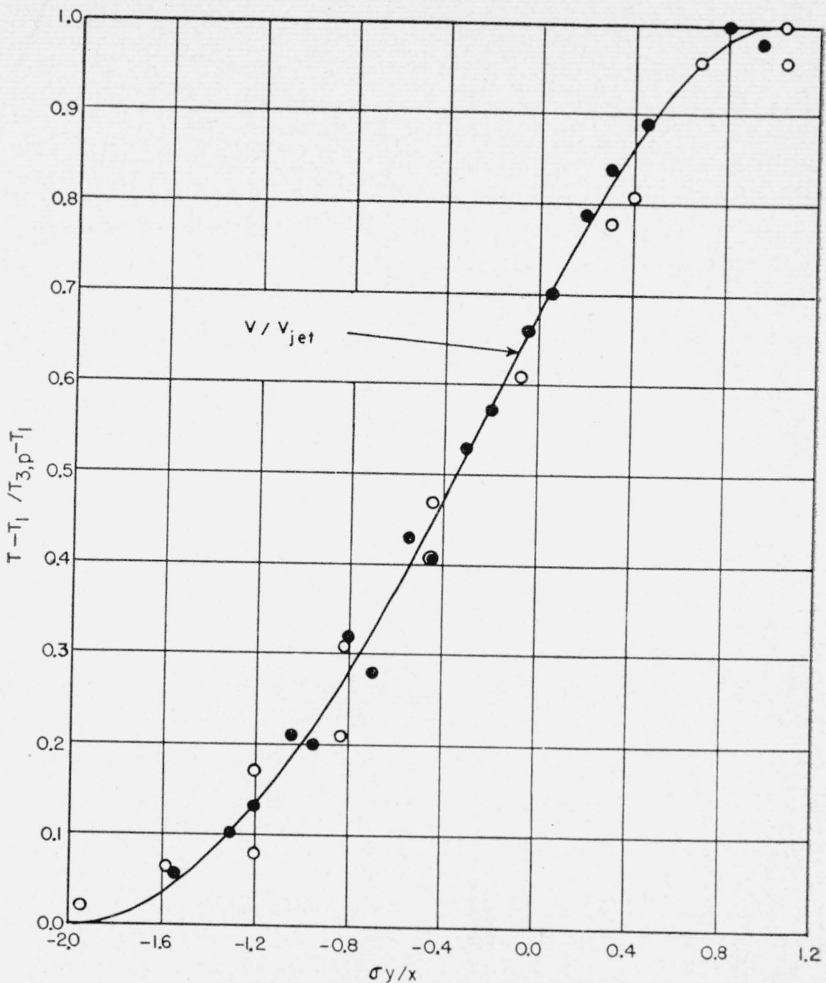

Figure 18. Free jet boundary.

$\mathrm{O}, x / r_{3, p}=4.50 ; \bullet, x / r_{3, p}=6.75 ; \sigma=12$.

Because the rate of flow differed by 65 percent, $\left(V_{3, s}-V_{3, p}\right)$ also differed by this amount. Three out of four comparisons of $r_{m}$ show that the magnitude of $V_{3,5}-V_{3, p}$ has little affect on the field. At an axial distance of $18 r_{3 . p}$, the maximum temperature was beyond the range of the temperature recorder in one of the runs, and consequently the radius plotted (broken circle) is somewhat greater than the true value. It is expected that agreement would be better than indicated in figure 17 at this axial distance. On the basis that $r_{m}$ is not affected, it is concluded that velocity ratio, rather than velocity difference, determines the mixing field. This same effect was evident in another comparison in which $V_{3, s}$ was about $0.1 \quad V_{3, p}$. Forstall and Shapiro reached this same conclusion.

In the region of the potential core, it may be said that the mixing region approximates that of a twodimensional region between semiinfinite moving streams differing in both temperature and velocity. In recent years the problem of mixing in the twodimensional case, with the mixing region bounded on one side by a quiet body of gas, has received considerable attention. Tollmien [1] presented a calculation of the velocity profile for incompressible flow, and much of the experimental work has been based on the determination of a scale factor $\sigma$ to match the experimental with the theoretical profile. The magniture of $\sigma$ may be regarded as an inverse measure of the rate of mixing.

A comparison of the temperature profile in the region of the potential core with Tollmien's profile 
of velocity in a free jet boundary is presented in figure 18. A test in which $V_{3, s} / V_{3, p}$ was 0.12 was selected as it was the nearest approach in the present series of experiments to the condition of still gas on one side of the mixing region. The other important difference is, of course, the large difference of temperature and density between the streams in these experiments. It appears that a value of $\sigma=12$ brings a fair correspondence between the data and the curve. Liepmann and Laufer [8] report a value of 12 based on their own and other measurements of velocity in a subsonic jet. However, the conditions differ in several respects as mentioned, and no firm conclusions can therefore be drawn about the relative mixing rate, and these data are presented merely as information. Values of $\sigma$ were also determined when $V_{3, s} / T_{3, p}$ was larger than unity, and these ranged as high as 18.

\section{Conclusion}

The problems of flow, heat release, and mixing in an equivalent gas turbine combustion chamber have been examined analytically. A large primary zone is advantageous, but the area is limited to about 60 percent of the total cross-sectional area. Practical experience has also led to the use of chambers of about this size relationship. Method of control currently used, although no doubt simple, leads to poor mixture quality in the primary zone and therefore puts a burden on the combustion process, which experience shows it cannot always overcome. Requirements for and effects of a possible means of mixture control are determined analytically. Experimental work demonstrates that the analytical method gives a good description of the flow, heat release, and mixing in the controlled combustion chamber. Although the control described would complicate the structure of the chamber, improve. ments in combustion could be a compensation.

Study of the mixing of primary flame gas and secondary air, and comparison with other studies of mixing reveals a general similarity. Ratio of velocity of the streams, not the velocity difference, determines the field of mixing, but the shape of the generalized profile of lateral spread of the mixing region is not affected by velocity. Temperature is transferred at a greater rate than velocity, and this conclusion also appears to be general in other studies. Some difference is noted, in that the combustion chamber has a characteristic length that may be regarded as the extent of the undisturbed potential core of temperature of the primary stream. In the incompressible case the extent of the core of velocity is variable with velocity ratio. In the region of the potential core a convergence of the radius of half maximum temperature is noted, while under similar conditions in the incompressible case there is a divergence. Beyond this region, the radius of half maximum temperature appears to have the normal divergence. Axial distribution of temperature is similar to distribution of velocity, and when expressed with reference to the temparature of the secondary stream, an inverse relationship with axial distance is obtained. This inverse relationship, which holds without regard to velocity ratio, is of general utility in the determination of the tempera. ture field, especially when it is noted that the chamber has a characteristic length. On the basis of rate of approach of axial temperature to average or "mixed" outlet temperature, the mixing process is least effective when the velocities of the streams are equal. Comparison of the field in this with that in the incompressible case leads to the conclusion that the effect of the large difference of temperature or density between the streams is to retard mixing.

\section{References}

[1] W. Tollmien, Calculation of turbulent expansion processes, translation, Natl. Advisory Comm. Aeronaut. Tech. Mem. 1085' (1945).

[2] H. B. Squire and J. Trouncer, Round jets in general stream, ARC (Gt. Brit.) Report 1974 (Jan. 1944).

[3] F. R. Caldwell, F. W. Ruegg, and L. O. Olsen, Combustion in moving air, SAE Quarterly Transactions 3, 327 (1949).

[4] Wright Field Central Air Documents Office, An experimental Ir-IrRh thermocouple with cooled support, July 1949, Air Technical Index No. 58661.

[5] F. W. Ruegg and C. Halpern, Gravimetric analysis of exhaust gas from gas turbine combustion chambers, J. Research NBS 45, 113 (1950) RP2117.

[6] S. I. Pai, Two-dimensional jet mixing of a compressible fluid, J. Aeronaut. Sci. 16, 463 (1949).

[7] W. Forstall and A. H. Shapiro, Momentum and mass transfer in coaxial gas jets, J. Applied Mech. 17, 399 (1950).

[8] H. W. Liepman and J. Laufer, California Institute of Technology, Investigations of free turbulent mixing, Natl. Advisory Comm. Aeronaut. Tech. Note 1257 (1947).

Washington, July 2, 1952. 